Cite this: Chem. Sci., 2014, 5, 865

\title{
Earth-abundant hydrogen evolution electrocatalysts
}

\author{
James R. McKone, Smaranda C. Marinescu, Bruce S. Brunschwig, Jay R. Winkler \\ and Harry B. Gray* \\ Received 19th June 2013 \\ Accepted 4th November 2013 \\ Splitting water to hydrogen and oxygen is a promising approach for storing energy from intermittent \\ renewables, such as solar power. Efficient, scalable solar-driven electrolysis devices require active \\ electrocatalysts made from earth-abundant elements. In this mini-review, we discuss recent \\ DOI: $10.1039 / c 3 s c 51711 j$ \\ www.rsc.org/chemicalscience \\ investigations of homogeneous and heterogeneous hydrogen evolution electrocatalysts, with emphasis \\ on our own work on cobalt and iron complexes and nickel-molybdenum alloys.
}

\section{Introduction}

Sunlight is the only renewable energy source that alone can scale to levels required to replace fossil fuels. ${ }^{1}$ Although solar is quickly approaching cost parity with traditional fuels, ${ }^{2}$ the temporal intermittency of sunlight limits the scale at which solar technologies can be incorporated into the energy mix. ${ }^{3,4}$ Indeed, current solar technologies contribute mainly to electricity usage, and electricity itself accounts for approximately $40 \%$ of total energy use in the United States. ${ }^{5}$

Several methods for storing electricity derived from photovoltaics and other intermittent renewables are available, but all have drawbacks. For example, pumped hydro energy storage is efficient and inexpensive, but limited by geographic requirements. ${ }^{6,7}$ Large-scale electricity storage in batteries is efficient, but suffers from high cost and low energy density. ${ }^{8}$ Water electrolysis is also a promising mode of energy storage, as it is possible to obtain reasonably high efficiency and high energy density using hydrogen compressed in high-pressure cylinders. ${ }^{9,10}$

Photovoltaics and water electrolysis are both mature technologies, but current-generation photovoltaic modules and electrolyzers do not provide electricity and hydrogen, respectively, at costs comparable to existing fossil fuel sources. Therefore, innovations are needed to realize solar energy storage technologies that are competitive with non-renewable fuels. Many research groups, including ours, have focused on the development of integrated solar water splitting systems based on the direct coupling of semiconductor light absorbers with catalytic species. ${ }^{11-15}$ Several other approaches to solardriven electrolysis are also being studied with respect to their technological and economic feasibility. ${ }^{16,17}$

Division of Chemistry and Chemical Engineering and the Beckman Institute, California Institute of Technology, Pasadena, CA 91125, USA. E-mail: hbgray@caltech.edu
Whether or not they are driven by sunlight, water electrolysis devices require efficient catalysts for electrochemical hydrogen and oxygen evolution. Notably, catalysts based on platinum, the industry standard for proton exchange membrane (PEM) electrolysis, are not likely to be viable for solar water splitting schemes. This is because PEM electrolyzer systems would require millions of $\mathrm{kg}$ of $\mathrm{Pt}$ to store even a small proportion of the global energy demand, whereas the total global annual Pt production is only $\sim 200000 \mathrm{~kg}$ per year. ${ }^{18}$ Therefore earthabundance is a key requirement for materials to be used in highly scalable water splitting systems.

Much work has gone into evaluating homogeneous and heterogeneous hydrogen evolution catalysts for applications in efficient, scalable energy storage. Molecular species or solid compounds may be used to catalyze electrochemical or photochemical hydrogen evolution, and they may either be attached to an electrode surface or freely diffusing in solution. While molecular compounds have played a primary role in elucidating mechanistic details of hydrogen evolution electrocatalysis, solid catalysts have generally performed better in functional systems.

Here we present a mini-review of recent work on homogeneous and heterogeneous hydrogen evolution electrocatalysts. To differentiate our article from other reviews, ${ }^{19-31}$ we emphasize elucidation of mechanisms employed by homogeneous catalysts, especially those incorporating cobalt. Additionally, we discuss recent work on $\mathrm{Ni}$-Mo composites as earth-abundant heterogeneous catalysts for solar-driven hydrogen evolution.

\section{Homogeneous systems}

Enzymes can perform the hydrogen evolution reaction (HER) efficiently through nickel and iron cofactors, which evolve hydrogen catalytically near the thermodynamic potential with turnover frequencies as high as $9000 \mathrm{~s}^{-1}$ at $30^{\circ} \mathrm{C} \cdot{ }^{32,33}$ However, the relative instability of these enzymes under aerobic conditions has led to a search for robust inorganic compounds that 
can produce hydrogen from water. Platinum is an excellent catalyst for proton reduction and hydrogen oxidation, but scarcity and high cost limit its widespread use.

Considerations of cost and scalability have led to the development of catalysts for hydrogen evolution that employ earthabundant metals. ${ }^{21,23,34-36}$ While homogeneous catalysts typically degrade faster than their heterogeneous counterparts, molecular systems are easier to study mechanistically, and several research groups, including ours, have undertaken extensive efforts to synthesize and characterize such electrocatalysts. It is our view that understanding the fundamental mechanisms of electrocatalytic hydrogen evolution will aid the design of better homogeneous and heterogeneous catalysts.

\section{Work on molecular systems}

Recent work has yielded molecular HER catalysts using a variety of transition metals with higher abundance than Pt. DuBois reported the production of $\mathrm{H}_{2}$ in acetonitrile solution with turnover frequencies above $100000 \mathrm{~s}^{-1}$ for a family of mononuclear nickel-phosphine complexes (1, Fig. 1) containing pendant proximal bases. ${ }^{37}$ The proposed mechanism of proton reduction and hydrogen oxidation with nickel-phosphine complexes involves the cooperative interaction of $\mathrm{H}_{2}$ with both the metal center and multiple proton relays incorporated in the second coordination sphere..$^{25,26,38}$ Molybdenum oxo (2) ${ }^{39}$ and molybdenum sulfide $(3)^{40}$ species also catalytically generate hydrogen from water. Related cobalt species catalyze the hydrogen evolution reaction, albeit at high overpotentials. ${ }^{\mathbf{4 1 - 4 4}}$ Co-diglyoxime complexes (4) generate $\mathrm{H}_{2}$ from protic solutions at overpotentials as low as $40 \mathrm{mV} .^{19,20,22,45-49}$ Recent reports indicate that cobalt dithiolene complexes (5) catalyze both photocatalytic and electrocatalytic hydrogen production from water, ${ }^{50,51}$ and a cobalt bis(iminopyridine) complex (6) also is a highly active electrocatalyst for water reduction in buffered aqueous media. ${ }^{52}$

Although molybdenum, cobalt, and nickel are more abundant than platinum, an even more attractive candidate for the catalytic metal center is iron, the most abundant transition metal. Savéant has shown that Fe porphyrin complexes such as $[(\mathrm{TPP}) \mathrm{Fe}(\mathrm{Cl})](7)$ catalyze hydrogen evolution, albeit at very negative $\mathrm{Fe}^{\mathrm{II} / \mathrm{I}}$ potentials (below $-1.5 \mathrm{~V}$ vs. $\left.\mathrm{SCE}\right) .{ }^{53-56}[(\mathrm{bdt}) \mathrm{Fe}(\mathrm{P}-$ $\left.\left.\mathrm{Me}_{3}\right)_{2}(\mathrm{CO})_{2}\right](8)$ (bdt $=1,2$-benzenedithiolate) also catalyzes hydrogen evolution at similar potentials. ${ }^{57,58}$ Biomimetic diiron complexes, ${ }^{59-64}$ such as 9 (ref. 24, 65 and 66) and 10, ${ }^{67,68}$ act as hydrogen evolution catalysts at potentials in the range -1 to $-2 \mathrm{~V} v s$. SCE. The mechanism of hydrogen evolution catalyzed by diiron complexes, as proposed by Darensbourg, involves the reduction of the $\mathrm{Fe}^{\mathrm{I}} \mathrm{Fe}^{\mathrm{I}}$ parent complex to $\mathrm{Fe}^{0} \mathrm{Fe}^{\mathrm{I}}$, followed by uptake of protons to generate $\left(\eta^{2}-\mathrm{H}_{2}\right) \mathrm{Fe}^{\mathrm{II}}-\mathrm{Fe}^{\mathrm{I}}{ }^{69}$ a species believed to be a key intermediate in the electrochemical pathway for hydrogen evolution. We have found that iron complexes containing the fluorinated ligand 1,2-bis(perfluorophenyl)ethane-1,2-dionedioxime $\left[\left(\mathrm{dAr}^{\mathrm{F}} \mathrm{gBF}\right)_{2} \mathrm{Fe}(\mathrm{py})_{2}\right](\mathbf{1 1})$ act as electrocatalysts for hydrogen evolution at $-0.9 \mathrm{~V} v s$. SCE with a turnover frequency (TOF) of $20 \mathrm{~s}^{-1} \cdot{ }^{70}$ The corresponding monofluoroborated, proton-bridged complex $\left[\left(\mathrm{dAr}^{\mathrm{F}} \mathrm{g}_{2} \mathrm{H}-\mathrm{BF}_{2}\right)\right.$ $\left.\mathrm{Fe}(\mathrm{py})_{2}\right]$ displayed an improved TOF of $200 \mathrm{~s}^{-1}$ at $-0.8 \mathrm{~V}$.

\section{Mechanism of hydrogen evolution.}

Given the broad interest and potential applications of artificial photosynthesis, we focused on elucidating mechanisms of cobalt-catalyzed hydrogen evolution, an area where there have been both experimental ${ }^{45,47,71-78}$ and theoretical investigations. ${ }^{79-82}$ All of the proposed mechanisms (Scheme 1) begin with reduction of $\mathrm{Co}^{\mathrm{II}}$ to $\mathrm{Co}^{\mathrm{I}}$, followed by protonation to generate $\mathrm{Co}^{\mathrm{III}}-\mathrm{H}$. Hydrogen evolution can occur via protonation of $\mathrm{Co}^{\mathrm{III}}-\mathrm{H}$ or upon the bimolecular combination of two $\mathrm{Co}^{\mathrm{III}}-\mathrm{H}$ species. Alternatively, $\mathrm{Co}^{\mathrm{III}}-\mathrm{H}$ can be further reduced to $\mathrm{Co}^{\mathrm{II}}-\mathrm{H}$, which can react via similar homolytic or heterolytic pathways to produce hydrogen.

The mechanistic details of cobalt-catalyzed hydrogen evolution imply different optimum operating conditions. For example, if the bimolecular reaction of two $\mathrm{Co}^{\mathrm{III}}-\mathrm{H}$ species is the predominant pathway, then, for an efficient process, two
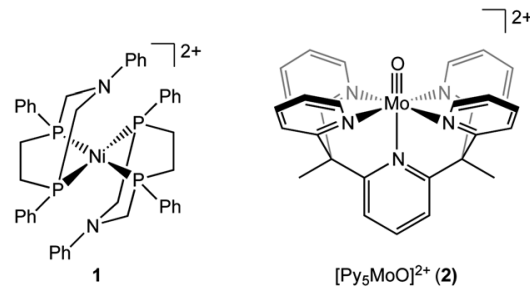

$\left[\mathrm{Py}_{5} \mathrm{MoO}^{2+}(\mathbf{2})\right.$ $\mathbf{3}=\left[\mathrm{Py}_{5} \mathrm{MoS}_{2}\right]^{2+}$

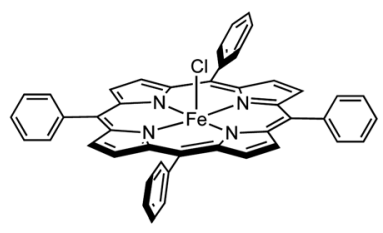

7

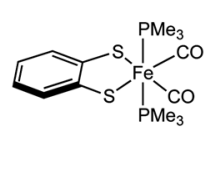

8
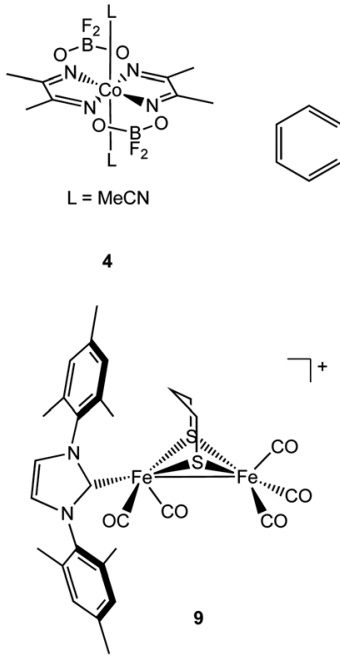

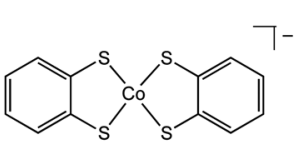

5

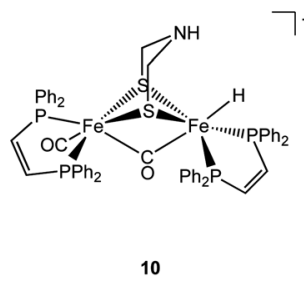

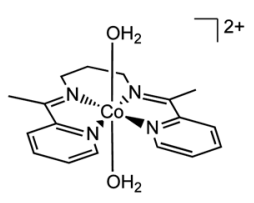

6

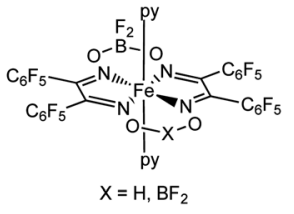

11

Fig. 1 Selected molecular hydrogen-evolving catalysts. 


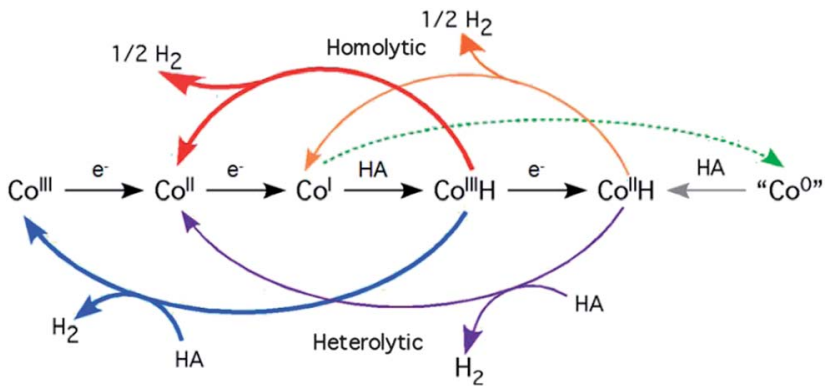

Scheme 1 Homolytic and heterolytic pathways for hydrogen evolution catalyzed by cobalt complexes, from ref. 34. Copyright 2009, the American Chemical Society, used with permission.

$\mathrm{Co}^{\mathrm{III}}-\mathrm{H}$ species should be immobilized in close proximity to one another on a cobaloxime-modified electrode. Accordingly, understanding basic mechanistic details of HER electrocatalysis might inform the design of catalyst candidates for subsequent research.

All of the previously discussed mechanisms invoke a key reactive intermediate, $\mathrm{Co}^{\mathrm{III}}-\mathrm{H}$, which has only recently been observed directly. ${ }^{83}$ Several cobalt hydride species supported by phosphine ligands, however, have been reported. ${ }^{84-90}$ Some examples are $\left[\mathrm{CpCo}^{\mathrm{III}} \mathrm{H}(\mathrm{P})_{2}\right]^{+}\left(\mathrm{P}=\mathrm{PPh}_{3}, \mathrm{PEt}_{3}, \mathrm{P}(\mathrm{OMe})_{3}\right)$ and $\left[\mathrm{CpCo}^{\mathrm{III}} \mathrm{H}\left(\mathrm{P}_{2}\right)\right]^{+}\left(\mathrm{P}_{2}=\mathrm{PPh}_{2} \mathrm{CH}_{2} \mathrm{PPh}_{2}, \mathrm{PPh}_{2} \mathrm{CH}_{2} \mathrm{CH}_{2} \mathrm{PPh}_{2}\right.$, or $\mathrm{PPh}_{2} \mathrm{CH}=\mathrm{CHPPh}_{2}$ (12, Fig. 2)), generated by protonation of $\left[\operatorname{CpCo}^{\mathrm{I}}(\mathrm{P})_{2}\right]$ and $\left[\mathrm{CpCo}^{\mathrm{I}}\left(\mathrm{P}_{2}\right)\right]$, respectively, with ammonium ions. ${ }^{91}$ These cobalt hydride complexes have been characterized by ${ }^{1} \mathrm{H}$ NMR spectroscopy. DuBois and coworkers investigated the ability of Co hydrides, such as $[\mathrm{CoH}(\mathrm{dppe})(\mathrm{MeCN})]^{2+}$ (dppe $=$ bis(diphenylphosphino)ethane) (13-15), to act as hydride donors. ${ }^{92}$ Cobalt(III) hydrides supported by tripodal $\left(16,{ }^{88,89} 17\right.$ (ref. 93)) or tetrapodal $\left(18,{ }^{84} 19\right.$ (ref. 86)) phosphine ligand frameworks have also been reported. The hydridocobaloxime $\left[\mathrm{HCo}(\mathrm{dmgH})_{2} \mathrm{P}\left(n-\mathrm{C}_{4} \mathrm{H}_{9}\right)_{3}\right](20)$, a proposed HER intermediate, was reported much earlier by Schrauzer and Holland. ${ }^{78}$ Interestingly, a broad ${ }^{1} \mathrm{H}$ NMR signal at $\delta=6.0 \mathrm{ppm}$ was assigned to a hydride, a surprising value for this ligand. Almost 40 years later, Artero and Fontecave employed a combined theoretical and experimental approach to show that this "hydride" was more likely an isomeric bridge-protonated cobalt $(\mathrm{I})$ species (21)..$^{77}$

Recent work in our group examining the mechanism of hydrogen evolution from a photogenerated hydridocobaloxime suggests that reaction via protonation of $\mathrm{CO}^{\mathrm{II}}-\mathrm{H}$ is favored under certain conditions, such as in solutions where $\mathrm{Co}^{\mathrm{III}}-\mathrm{H}$ is in low concentrations and reducing equivalents are in excess. ${ }^{74}$ We employed laser flash-quench techniques to investigate electron-transfer kinetics and the barriers to redox interconversions in cobaloxime complexes: in one study, a photoacid, 6-bromo-2-naphthol $\left({ }^{\mathrm{Br}} \mathrm{NaphOH}\right)$, was used to monitor $\mathrm{Co}^{\mathrm{I}}$ protonation and hydrogen evolution; laser transient spectroscopic measurements revealed that excited-state proton transfer from ${ }^{\mathrm{Br}} \mathrm{NaphOH}$ to $\left[(\mathrm{dmg})_{2} \mathrm{Co}^{\mathrm{I}}\left(\mathrm{CH}_{3} \mathrm{CN}\right)\right]^{-}$produces $\left[(\mathrm{dmg})_{2} \mathrm{Co}^{\mathrm{III}}(\mathrm{H})\left(\mathrm{CH}_{3} \mathrm{CN}\right)\right]$ with a rate constant of $4(1) \times 10^{9} \mathrm{M}^{-1}$ $\mathrm{s}^{-1}$ (Fig. 3).

Two additional processes appeared in the transient kinetics: a faster phase that exhibited a first-order dependence on the $\left[(\mathrm{dmg})_{2} \mathrm{Co}^{\mathrm{I}}\left(\mathrm{CH}_{3} \mathrm{CN}\right)\right]^{-}$concentration; and a slower phase that

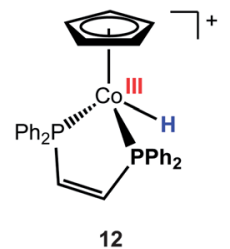

12

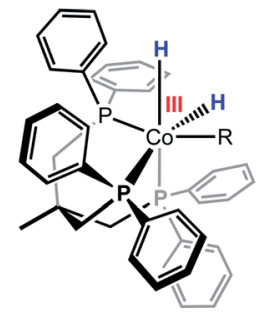

$\mathrm{R}=\mathrm{SnPh}_{3}, \mathrm{SnBu}_{3}, \mathrm{SiPh}_{3}$

16

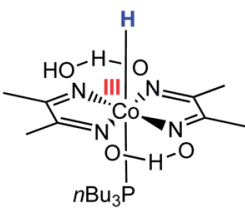

20

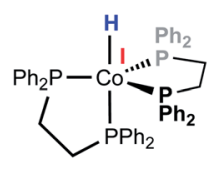

13

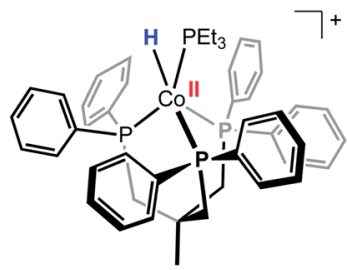

17

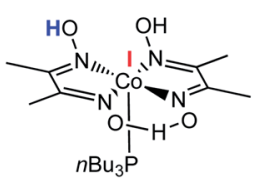

21

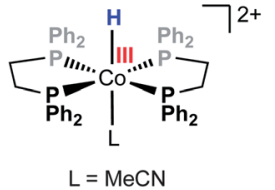

14

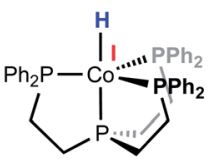

18

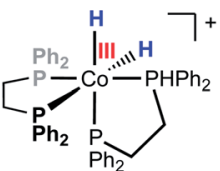

15

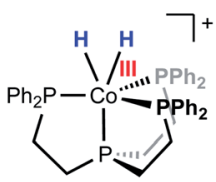

19

Fig. 2 Cobalt complexes related to HER intermediates. 

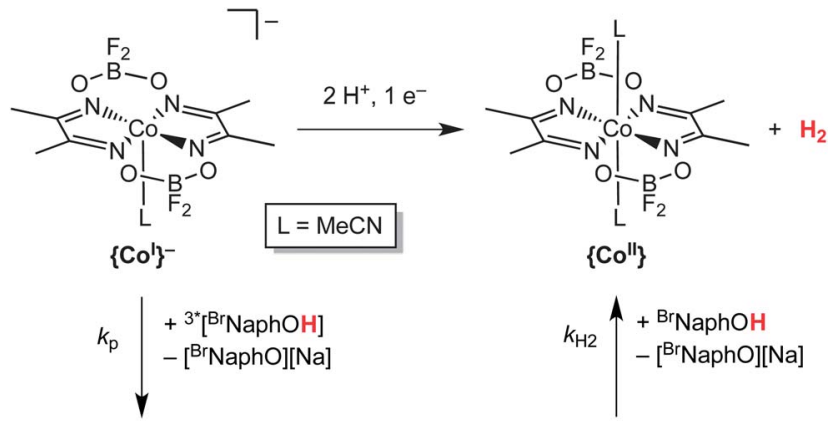

$k_{\mathrm{H} 2}\left\{\begin{array}{l}+{ }^{\mathrm{BrNaphOH}} \\ -\left[{ }^{\mathrm{Br}} \mathrm{NaphO}\right][\mathrm{Na}]\end{array}\right.$

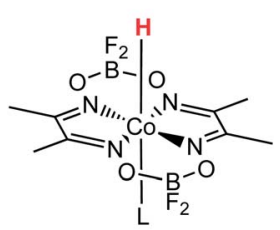

$\left\{\mathrm{Co}^{\mathrm{III}-\mathrm{H}}\right\}$

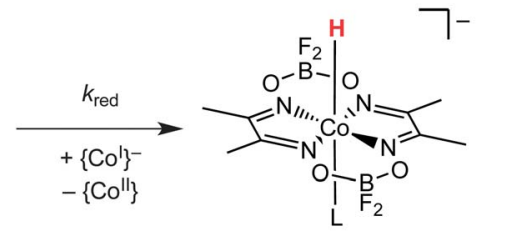

$\left\{\mathrm{Co}^{\prime \prime}-\mathrm{H}\right\}^{-}$

$$
\begin{aligned}
& k_{p}=3.0-4.7 \cdot 10^{9} \mathrm{M}^{-1} \mathrm{~s}^{-1} \\
& k_{\text {red }}=5.7 \cdot 10^{6} \mathrm{M}^{-1} \mathrm{~s}^{-1} \\
& k_{\mathrm{H} 2}=4.2 \cdot 10^{4} \mathrm{M}^{-1} \mathrm{~s}^{-1}
\end{aligned}
$$

Fig. 3 Kinetics parameters for reactions leading to hydrogen evolution from a cobaloxime.

was first order in the concentration of ${ }^{\mathrm{Br}} \mathrm{NaphOH}$. The former process, with a rate constant of $9(1) \times 10^{6} \mathrm{M}^{-1} \mathrm{~s}^{-1}$, corresponds to reduction of $\left[(\mathrm{dmg})_{2} \mathrm{Co}^{\mathrm{III}}(\mathrm{H})\left(\mathrm{CH}_{3} \mathrm{CN}\right)\right]$ by excess $\left[(\mathrm{dmg})_{2} \mathrm{Co}^{\mathrm{I}}\left(\mathrm{CH}_{3} \mathrm{CN}\right)\right]^{-}$to generate $\left[(\mathrm{dmg})_{2} \mathrm{Co}^{\mathrm{II}}(\mathrm{H})\left(\mathrm{CH}_{3} \mathrm{CN}\right)\right]^{-}$. The slower, acid dependent process arises from protonation of $\left[(\mathrm{dmg})_{2} \mathrm{Co}^{\mathrm{II}}(\mathrm{H})\left(\mathrm{CH}_{3} \mathrm{CN}\right)\right]^{-}$by ground-state ${ }^{\mathrm{Br}} \mathrm{NaphOH}\left(\mathrm{p} K_{\mathrm{a}}=\right.$ 26.1 in acetonitrile) to generate hydrogen and $\left[(\mathrm{dmg})_{2} \mathrm{Co}^{\mathrm{II}}\left(\mathrm{CH}_{3} \mathrm{CN}\right)_{2}\right]$. Two key observations emerged from these kinetics studies: $\left[(\mathrm{dmg})_{2} \mathrm{Co}^{\mathrm{I}}\left(\mathrm{CH}_{3} \mathrm{CN}\right)\right]^{-}$readily reduces $\left[(\mathrm{dmg})_{2} \mathrm{Co}^{\mathrm{III}}(\mathrm{H})\left(\mathrm{CH}_{3} \mathrm{CN}\right)\right]$, and $\left[(\mathrm{dmg})_{2} \mathrm{Co}^{\mathrm{II}}(\mathrm{H})\left(\mathrm{CH}_{3} \mathrm{CN}\right)\right]^{-}$reacts rapidly with extremely weak acids in a heterolytic fashion to evolve hydrogen.

Computational studies by Hammes-Schiffer ${ }^{79,80}$ and Muckerman $^{81}$ suggested that a mechanism involving a $\mathrm{Co}^{\mathrm{II}}-\mathrm{H}$ intermediate, generated by reduction of $\mathrm{Co}^{\mathrm{III}}-\mathrm{H}$, is likely. This suggestion also was supported by an experimental study of a hangman metalloporphyrin complex that provided strong evidence for formation of a $\mathrm{Co}^{\mathrm{II}}-\mathrm{H}$ intermediate before hydrogen evolution. ${ }^{94,95}$ Moreover, electrochemical studies of a covalently linked dicobaloxime revealed that the rate of hydrogen evolution was not significantly different from that of a monomeric analogue. ${ }^{96}$ These experiments suggested that hydrogen evolution likely occurs by protonation of reductively generated $\mathrm{CO}^{\mathrm{II}}-\mathrm{H}$ rather than homolysis of two $\mathrm{Co}^{\mathrm{III}}-\mathrm{H}$ units.

In very recent work, we found that a cationic cobalt $(\mathrm{I})$ complex supported by a triphos ligand framework (triphos = 1,1,1-tris(diphenylphosphinomethyl)ethane) reacts with $p$-toulenesulfonic acid to evolve hydrogen at room temperature. ${ }^{83}$ Cyclic voltammograms of $\left[(\text { triphos }) \mathrm{Co}^{\mathrm{I}}\left(\mathrm{CH}_{3} \mathrm{CN}\right)\right]^{+}(22)$ in acetonitrile feature a reversible $\mathrm{Co}^{\mathrm{II} / \mathrm{I}}$ oxidation wave at $-0.68 \mathrm{~V} v$ s. $\mathrm{Fc}^{+/ 0}$, an irreversible $\mathrm{Co}^{\mathrm{III} / \mathrm{II}}$ oxidation wave at $0.66 \mathrm{~V}$, an irreversible $\mathrm{Co}^{\mathrm{I} / 0}$ reduction wave at $-1.81 \mathrm{~V}$, and an irreversible
$\mathrm{Co}^{0 /-1}$ wave at $-2.73 \mathrm{~V}$. Voltammograms recorded with varying concentrations of $p$-toulenesulfonic acid monohydrate $\left(\mathrm{TsOH} \cdot \mathrm{H}_{2} \mathrm{O}\right)$ exhibit current enhancements at potentials near those for the $\mathrm{Co}^{\mathrm{II} / \mathrm{I}}$ and $\mathrm{Co}^{\mathrm{I} / 0}$ couples, with a larger increase in catalytic current at potentials near those for the $\mathrm{Co}^{\mathrm{I} / 0}$ couple (Fig. 4).

Bulk electrolysis of $\left[(\text { triphos }) \mathrm{Co}^{\mathrm{I}}\left(\mathrm{CH}_{3} \mathrm{CN}\right)\right]^{+}$at $-1.0 \mathrm{~V} v$ s. $\mathrm{Fc}^{+/ 0}$ in the presence of $\mathrm{TsOH} \cdot \mathrm{H}_{2} \mathrm{O}$ and $0.1 \mathrm{M} n-\mathrm{Bu}_{4} \mathrm{NPF}_{6}$ in acetonitrile generated hydrogen with a faradaic yield of $99 \pm 10 \%$. Addition of $\mathrm{TsOH} \cdot \mathrm{H}_{2} \mathrm{O}$ to a $\left[(\text { triphos }) \mathrm{Co}^{\mathrm{I}}\left(\mathrm{CH}_{3} \mathrm{CN}\right)\right]^{+}(22)$ solution produced a color change from blue to yellow/green, and NMR spectra of the reaction mixture indicated formation of hydrogen and $\left[(\text { triphos }) \mathrm{Co}^{\mathrm{II}}(\mathrm{TsO})\left(\mathrm{CH}_{3} \mathrm{CN}\right)\right]^{+}(\mathbf{2 3})$, as evidenced also by $\mathrm{X}$-ray crystallography (Scheme 2). Analysis of the products confirmed generation of 0.5 equivalents of hydrogen. The ${ }^{1} \mathrm{H}$ NMR spectrum recorded immediately after the addition of 10 equivalents of $\mathrm{TsOH} \cdot \mathrm{H}_{2} \mathrm{O}$ to a solution of [(triphos)$\left.\mathrm{Co}^{\mathrm{I}}\left(\mathrm{CH}_{3} \mathrm{CN}\right)\right]^{+}(22)$ revealed a doublet of triplets at $\delta-7.6 \mathrm{ppm}$ (coupling constants: $J_{\text {cis-P-H }}=65 \mathrm{~Hz} ; J_{\text {trans-P-H }}=130 \mathrm{~Hz}$ ), indicative of a hydride signal, as expected in [(triphos)$\left.\mathrm{Co}^{\mathrm{III}}(H)\left(\mathrm{CH}_{3} \mathrm{CN}\right)_{2}\right]^{2+}(\mathbf{2 4})$. The ${ }^{31} \mathrm{P}$ NMR spectrum displayed two peaks in a $2: 1$ ratio, confirming the assignment (protonation of $\mathrm{Co}^{\mathrm{I}}$ produces a transient $\mathrm{Co}^{\mathrm{III}}-\mathrm{H}$ complex).

Our observation of $\mathrm{Co}^{\mathrm{III}}-\mathrm{H}$ allowed direct probing of the mechanisms proposed for cobalt catalyzed hydrogen evolution (Scheme 3). Direct protonation of $\mathrm{Co}^{\mathrm{III}}-\mathrm{H}$ to produce $\mathrm{Co}^{\mathrm{III}}$ and $\mathrm{H}_{2}$, as in mechanism 1, was expected to display a first-order dependence on $\left[\mathrm{Co}^{\mathrm{III}}-\mathrm{H}\right]$. The bimolecular reaction between two $\mathrm{Co}^{\mathrm{III}}-\mathrm{H}$ complexes (mechanism 2) was expected to display a second-order dependence on $\left[\mathrm{Co}^{\mathrm{III}}-\mathrm{H}\right]$ and no dependence on acid concentration. For the third pathway (mechanism 3), the reduction of $\mathrm{Co}^{\mathrm{III}}-\mathrm{H}$ by $\mathrm{Co}^{\mathrm{I}}$ to generate $\mathrm{Co}^{\mathrm{II}}-\mathrm{H}$ and $\mathrm{Co}^{\mathrm{II}}$, the rate of the reaction should be second order in $\left[\mathrm{Co}^{\mathrm{III}}-\mathrm{H}\right]$ and inverse order in $[\mathrm{HA}]\left(\left[\mathrm{Co}^{\mathrm{I}}\right]\right.$ can be obtained from the pre-equilibrium equation).

We investigated the decay kinetics of $\mathrm{Co}^{\mathrm{III}}-\mathrm{H}$ as a function of acid concentration (Fig. 5). ${ }^{83}$ The $\mathrm{Co}^{\mathrm{III}}-\mathrm{H}$ concentration exhibited an inverse dependence on reaction time, consistent with a reaction that is second order in the concentration of $\mathrm{Co}^{\mathrm{III}}-\mathrm{H}$. We also found a decreasing rate constant with

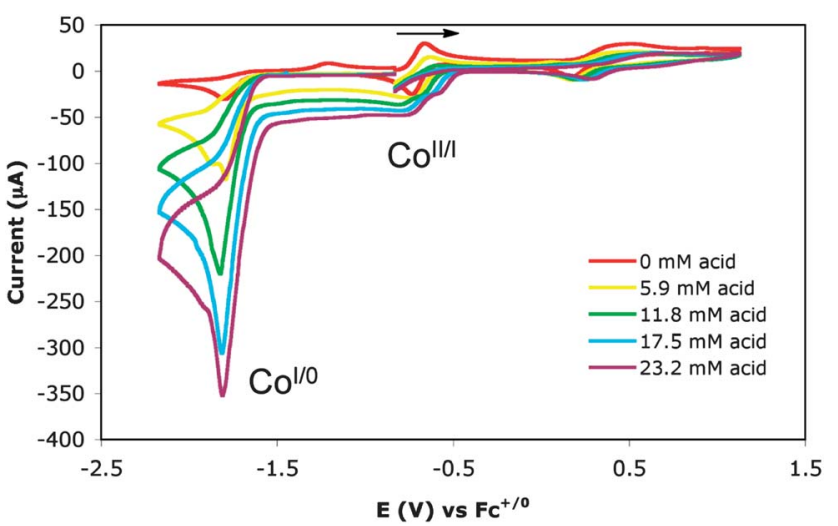

Fig. 4 Cyclic voltammograms of $\left[(\text { triphos }) \mathrm{Co}^{\prime}\left(\mathrm{CH}_{3} \mathrm{CN}\right)\right]^{+}(22)$ in $0.1 \mathrm{M}$ $\left[n \mathrm{Bu}_{4}\right]\left[\mathrm{PF}_{6}\right]$ acetonitrile solution in the presence of $\mathrm{TsOH} \cdot \mathrm{H}_{2} \mathrm{O}$. 


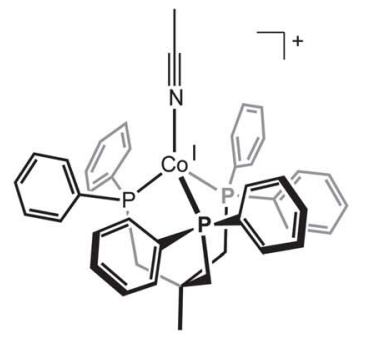

22
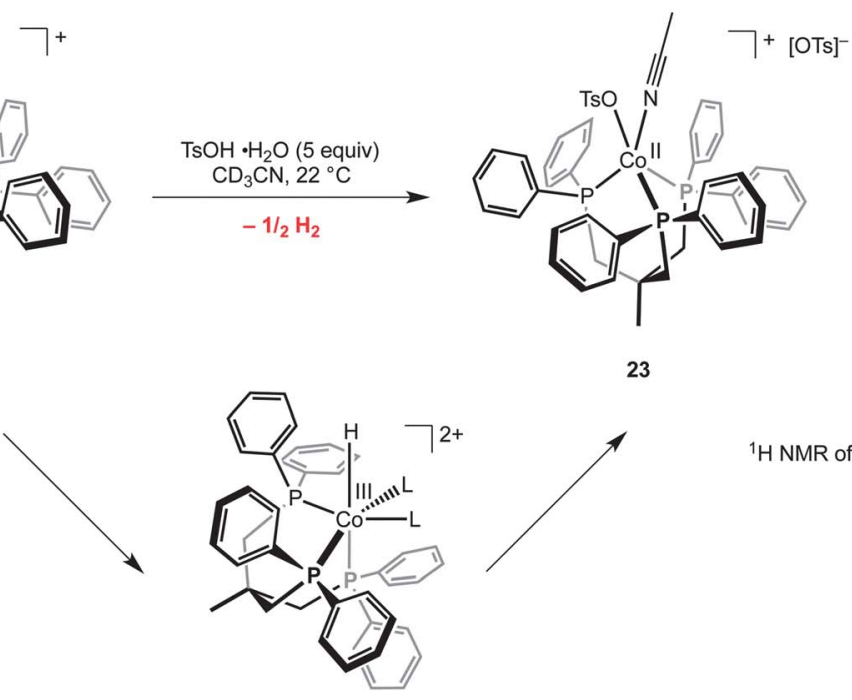

23

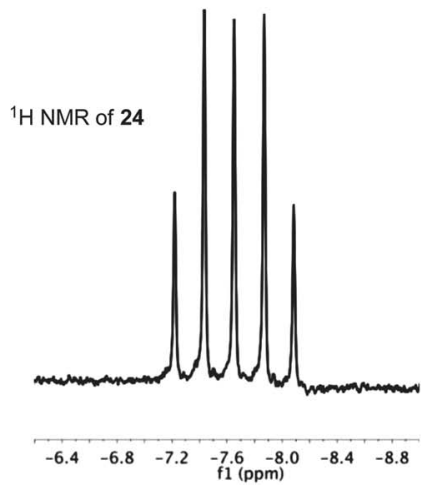

Scheme 2 Hydrogen evolution from a cationic cobalt(1) phosphine complex.

$$
\begin{aligned}
& \text { pre-equilibrium }\left\{\mathrm{Co}^{\prime}\right\}^{+}+\mathrm{HA} \underset{k_{-1}}{\stackrel{k_{1}}{\rightleftharpoons}}\left\{\mathrm{Co}^{\prime \prime \prime}-\mathrm{H}\right\}^{2+}+\mathrm{A}^{-} \quad \mathrm{K}=k_{1} / k_{-1} \quad K=\frac{k_{1}}{k_{-1}}=\frac{\left[C o^{\prime \prime \prime}-H\right]\left[A^{-}\right]}{\left[\mathrm{Co}^{\prime}\right][H A]} \\
& \text { Mechanism } 1 \\
& \left\{\mathrm{Co}^{\prime \prime \prime}-\mathrm{H}\right\}^{2+}+\mathrm{HA} \underset{k_{-2}}{\stackrel{k_{2}}{\rightleftharpoons}}\left\{\mathrm{Co}^{\prime \prime \prime}\right\}^{3+}+\mathrm{H}_{2}+\mathrm{A}^{-} \\
& \frac{d\left[C o^{\prime \prime \prime}-H\right]}{d t}=-k_{2}\left[C o^{\prime \prime \prime}-H\right][H A] \\
& \text { fast }\left\{\mathrm{Co}^{\prime \prime \prime}\right\}^{3+}+\mathrm{e}^{-} \longrightarrow\left\{\mathrm{Co}^{\prime \prime}\right\}^{2+} \\
& \text { - 1st order dependence on [Co } \left.{ }^{\prime \prime \prime}-H\right] \\
& \text { - 1st order dependence on [HA] } \\
& 2\left\{\mathrm{Co}^{\mathrm{III}-\mathrm{H}}\right\}^{2+} \\
& \underset{k_{-3}}{\stackrel{k_{3}}{\rightleftharpoons}} 2\left\{\mathrm{Co}^{\prime \prime}\right\}^{2+}+\mathrm{H}_{2} \\
& \text { Mechanism } 3
\end{aligned}
$$

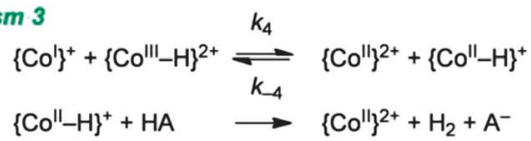

$$
\begin{aligned}
& \frac{d\left[C o^{\prime \prime \prime}-H\right]}{d t}=-k_{4}\left[\mathrm{Co}^{\prime}\right]\left[\mathrm{Co}^{\prime \prime \prime}-H\right]= \\
& =-k_{4} \frac{\left[C o^{\prime \prime \prime}-H\right]\left[A^{-}\right]}{K[H A]}\left[C o^{\prime \prime \prime}-H\right] \\
& \frac{d\left[C o^{\prime \prime \prime}-H\right]}{d t}=-\frac{k_{4}\left[A^{-}\right]}{K[H A]}\left[C o^{\prime \prime \prime}-H\right]^{2}
\end{aligned}
$$

Scheme 3 Proposed mechanisms for cobalt catalyzed hydrogen evolution, from the ESI of ref. 53.

increasing acid concentration, confirming that mechanism 3 in Scheme 3 is the predominant pathway. Analysis showed that the rate constant associated with the reduction of $\mathrm{Co}^{\mathrm{III}}-\mathrm{H}$ by $\mathrm{Co}^{\mathrm{I}}$ $\left(k_{4}=4.4 \times 10^{-2} \mathrm{M}^{-1} \mathrm{~s}^{-1}\right)$ is almost a factor of 20 higher than the one corresponding to the bimolecular reaction of $\mathrm{Co}^{\mathrm{III}}-\mathrm{H}\left(k_{3}=\right.$ $\left.2.5 \times 10^{-3} \mathrm{M}^{-1} \mathrm{~s}^{-1}\right)$. Electrochemical experiments also support the conclusion that hydrogen evolution proceeds almost exclusively by the pathway involving $\mathrm{Co}^{\mathrm{II}}-\mathrm{H}$, as large catalytic currents were observed upon formation of $\mathrm{Co}^{\mathrm{O}}$ (or $\mathrm{Co}^{\mathrm{II}}-\mathrm{H}$ in the presence of acid). Thus our homogeneous and electrochemical kinetics analyses demonstrated that $\mathrm{Co}^{\mathrm{II}}-\mathrm{H}$ is the active species for hydrogen evolution.

\section{Supported catalysts}

Immobilization of molecular species on semiconductor materials has gained recent interest. ${ }^{11}$ Several reports have focused on the development of efficient and robust electrode materials for hydrogen evolution in a scalable electrolysis or photoelectrolysis cell. In this context, the development of advanced 


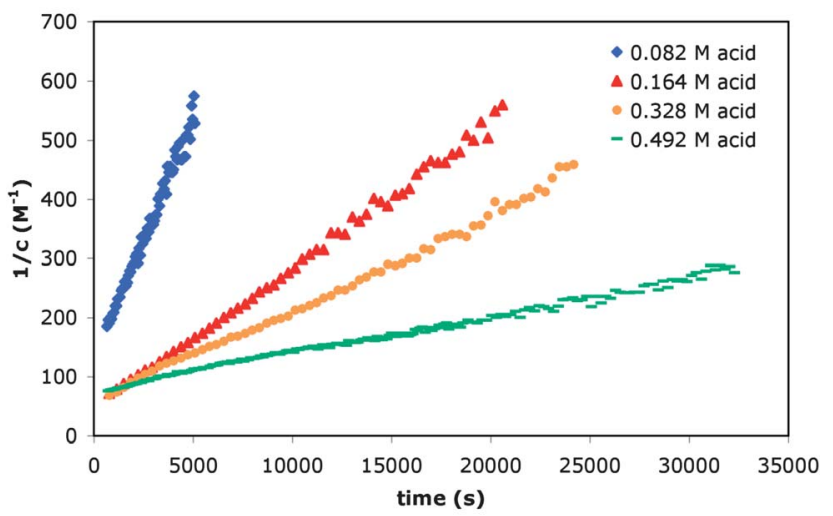

Fig. 5 Kinetics of CO"II-H (24) decay measured by ${ }^{1} \mathrm{H}$ NMR spectroscopy as a function of acid concentration.

materials and techniques has allowed significant progress such as the attachment of molecular sensitizers and catalysts to semiconductors for developing integrated photoanodes and photocathodes. Practical applications of these immobilized species require that these materials can operate under entirely aqueous conditions.

Peters and coworkers have reported that $\mathrm{Co}\left(\mathrm{dmgBF}_{2}\right)$ $(\mathrm{MeCN})_{2}(\mathrm{dmg}=$ dimethylglyoxime $)$ can be adsorbed on glassy carbon electrodes by controlled potential electrolysis at $-0.6 \mathrm{~V}$ vs. SCE for $1 \mathrm{~h} .{ }^{97}$ The chemically modified electrode material was active for hydrogen evolution in acidic aqueous solution $(\mathrm{pH}=2)$, with an overpotential of only $100 \mathrm{mV}$. Le Goff et al. have shown that the covalent attachment of a nickel bisdiphosphine system onto amine-modified multiwalled carbon nanotubes (MWCNTs) generates a high surface area cathode material (25, Fig. 6)..$^{8}$ The nickel functionalized MWCNTs material evolved hydrogen from a $0.2 \mathrm{M} n \mathrm{Bu}_{4} \mathrm{NPF}_{6}$ acetonitrile solution in the presence of [DMFH]OTf/DMF with an overpotential of $200 \mathrm{mV}$. The generated electrocatalytic material showed high activity towards the production and oxidation of hydrogen, as well as operation under acidic aqueous conditions (0.5 M sulfuric acid). These extreme conditions are required for catalyst viability in proton exchange membrane systems. In a similar fashion, a cobalt diimine-dioxime complex was grafted to the surface of a carbon nanotube electrode, and the resulting electrocatalytic cathode material (26) evolved hydrogen from aqueous solutions $(\mathrm{pH}=4.5)$ with an overpotential of $590 \mathrm{mV}$ at a current density of $1 \mathrm{~mA} \mathrm{~cm}{ }^{-2} \cdot{ }^{99} \mathrm{UV}$-induced immobilization chemistry of alkenes to visible light-absorbing semiconductors, such as p-type (100) GaP and p-type (111) Si, was used to generate photocathode materials that are relevant to light capture and conversion applications in artificial photosynthesis. ${ }^{100}$ This grafting procedure was used to generate the material 27. The catalytic activity of this material has not been reported. Another procedure involves UV-induced immobilization chemistry of vinylpyridine to p-type (100) GaP surface, followed by coordination of the cobaloxime complex $\left(\mathrm{Co}\left(\mathrm{dmgH}_{2}\right)\left(\mathrm{dmgH}^{2} \mathrm{Cl}_{2}\right)\right.$ to pyridine moieties to generate a photocathode material (28) that showed enhanced photochemical performance in aqueous conditions at neutral $\mathrm{pH}^{101}$
Despite these promising results, finding ways to immobilize catalysts on semiconductor surfaces remains a major challenge. If the catalysts are attached to light-absorbers, one of the requirements for an efficient device is to optimize absorber surface area and catalyst loading. Lowering the overpotentials and enhancing the stabilities of immobilized catalysts under aqueous acidic conditions are areas where much additional work is needed.

\section{Heterogeneous systems}

Heterogeneous hydrogen evolution was the subject of several of the earliest studies of electrode kinetics by Tafel. ${ }^{102,103}$ Subsequent efforts have shown that hydrogen evolution can proceed at metallic electrode surfaces through the following primary steps: ${ }^{104}$

$$
\begin{gathered}
\mathrm{HA}+{ }^{*} \stackrel{e^{-}}{\longrightarrow} \mathrm{H}^{*}+\mathrm{A}^{-} \\
\mathrm{H}^{*}+\mathrm{HA} \stackrel{e^{-}}{\longrightarrow} \mathrm{H}_{2}+\mathrm{A}^{-} \\
2 \mathrm{H}^{*} \rightarrow \mathrm{H}_{2}
\end{gathered}
$$

where the asterisk $(*)$ indicates a surface adsorption site. Eqn (1) is commonly known as the "discharge" or Volmer step, eqn (2) is known as the "atom + ion" or Heyrovsky step, and eqn (3) is known as the "atom + atom" or Tafel step. Hydrogen evolution proceeds through eqn (1) followed by either eqn (2) or (3). These heterogeneous mechanisms are directly analogous to the mononuclear and binuclear pathways for homogeneous hydrogen evolution catalysis.

Several theoretical, ${ }^{\mathbf{1 0 5 , 1 0 6}}$ experimental, ${ }^{107,108}$ and computational ${ }^{109-111}$ studies have concluded that the fastest reaction rate for heterogeneous hydrogen evolution can be obtained when the bond energy between hydrogen and the catalyst surface is optimized at an intermediate value. Hydrogen evolution activities of pure metals were collected by Trasatti ${ }^{108}$ (acidic conditions) and Miles ${ }^{107}$ (alkaline conditions) to construct what are known as "volcano plots" illustrating the correlation of activity with metal-hydrogen bond strength or periodic group. This relationship between activity and intermediate bond strength can be regarded as one of many manifestations of the Sabatier principle. ${ }^{112}$

Elucidating the mechanism of heterogeneous hydrogen evolution usually takes the form of Tafel analysis, where the steady state or quasi-steady state current, $i$, at a catalyst of a given composition is measured over a range of overpotential, $\eta$. Then $\log (i)$ can be plotted against $\eta$ to give a linear relationship, known as a Tafel line. The intercept of the Tafel line with the current axis gives the exchange current density, $i_{0}$, which is related to both the inherent reaction exchange rate at dynamic equilibrium and the electrochemically active surface area of the catalyst. The slope of the Tafel line is independent of surface area and takes on a limited number of values that correspond to the dominant mechanism. Generally Tafel slopes equal to $\frac{2.3 R T}{\alpha F}$ (or $\sim 120 \mathrm{mV}$ per decade for $\alpha=0.5$ at room temperature), where 


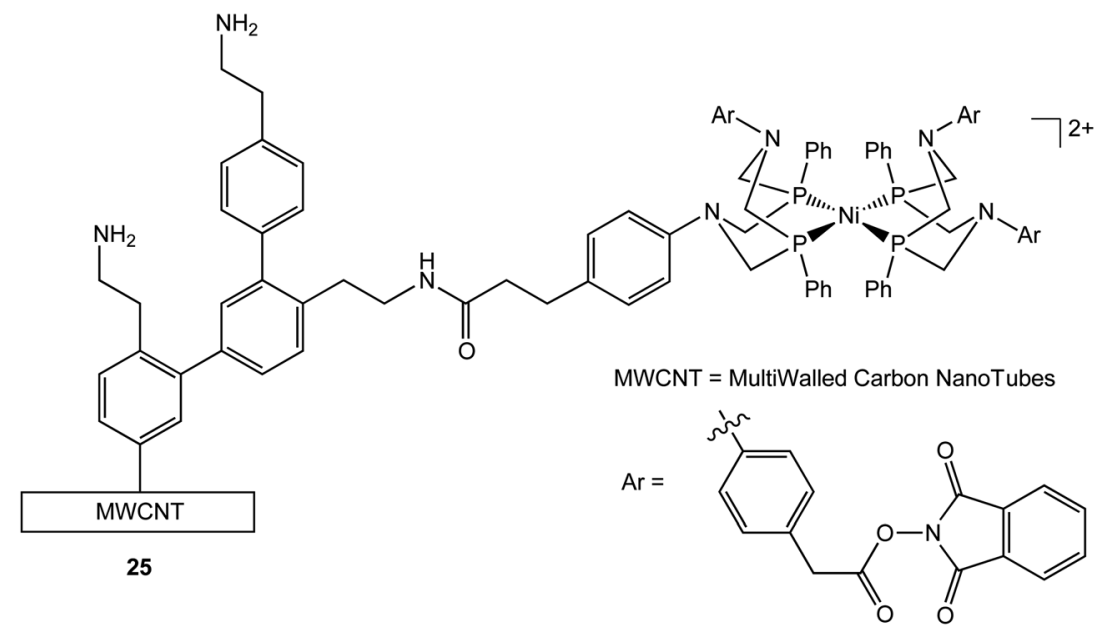

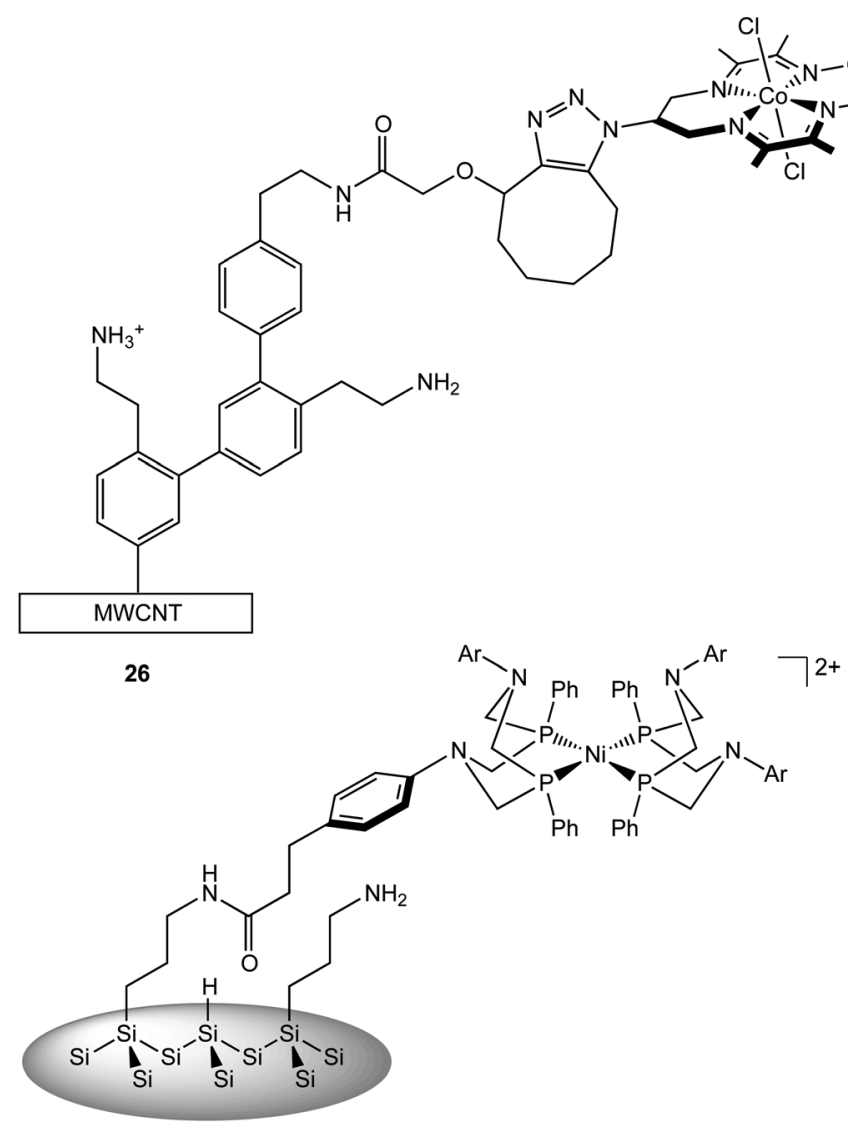

27

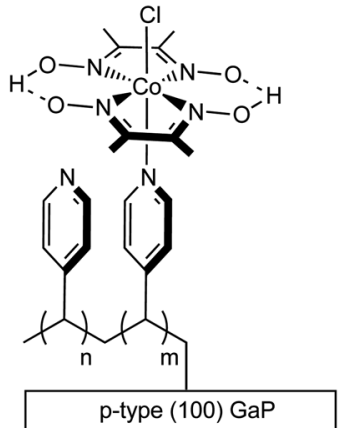

28

Fig. 6 Molecular hydrogen-evolving catalysts immobilized on solid materials.

$\alpha$ is the electrochemical transfer coefficient, ${ }^{113}$ are taken to indicate that the initial discharge step is rate-determining, whereas lower Tafel slopes indicate that either the atom + atom or ion + atom step is rate-determining. ${ }^{114}$ Additionally, if the electrochemically active surface area can be measured directly, $i$ at any overpotential can be converted through the Faraday constant to units of electrons $\mathrm{s}^{-1}$, normalized to the active surface area and the stoichiometric number of electrons transferred per turnover, and interpreted as a TOF.
Our research group has been interested in studying earth-abundant heterogeneous hydrogen evolution electrocatalysts for use in solar water splitting systems. Several earth-abundant heterogeneous catalyst candidates have recently emerged as particularly promising, including Mo sulfides and Ni-Mo composites. Recent developments in Mo sulfides have been reviewed elsewhere. ${ }^{115,116}$ In the following we discuss work on Ni-Mo composites. 


\section{Previous work on Ni-Mo}

Nickel-based composites have been studied for decades as hydrogen evolution catalysts in alkaline electrolyzers. ${ }^{\mathbf{1 0 4}}$ Composites based on mixtures of $\mathrm{Ni}$ and Mo exhibited the highest activity, stability, and they were therefore studied extensively. Work in the late 1950s and early 1960s showed that metallic molybdenum could be electrodeposited from aqueous solution as an alloy with iron-group metals, whereas pure molybdenum-containing solutions would only electrodeposit as the partially reduced oxide. ${ }^{117,118}$ Furthermore, the cooperative deposition of metallic material only proceeded under conditions where hydrogen also was evolved, implying unique interactions between $\mathrm{Ni}, \mathrm{Mo}$, and $\mathrm{H}_{2}$ or HER intermediates.

Researchers working for British Petroleum demonstrated in the early 1980s that Ni-Mo alloys synthesized by a pyrolysis/ reduction method exhibited the lowest reported overpotentials required to reach industrially relevant HER current densities for non-noble catalysts. ${ }^{119,120}$ Around the same time, Stachurski et al. patented a Ni-Mo-Cd catalyst that could be electrodeposited onto a substrate and exhibited high activity and stability under alkaline hydrogen evolution conditions. ${ }^{\mathbf{1 2 1}}$ This ternary catalyst was studied in detail by Conway, who concluded that adsorbed hydrogen or a surface hydride is responsible for the improved performance of $\mathrm{Ni}-\mathrm{Mo}-\mathrm{Cd}$ compared to pure Ni. ${ }^{122-125}$

In subsequent work, Raj and coworkers evaluated many Ni-based composites. ${ }^{\mathbf{1 2 6 - 1 3 1}}$ All of these composites were electrodeposited and tested under alkaline conditions over a range of temperatures. Those that were composed of Ni-Mo or NiMo-X, where $\mathrm{X}$ is another transition metal, consistently exhibited higher catalytic activities than those without $\mathrm{Ni}$ and Mo. These researchers focused particularly on the composite $\mathrm{Ni}-\mathrm{Mo}-\mathrm{Fe}$, as it exhibited the highest activity under alkaline conditions.

The mechanism by which Ni-Mo exhibits enhanced catalytic activity toward hydrogen evolution compared to pure Ni has not been established. Some authors have argued that bulk Ni-Mo is not inherently more active than $\mathrm{Ni}$, but instead exhibits higher activity merely as a result of increased surface area for highly porous coatings. ${ }^{\mathbf{1 2 4 , 1 3 2}}$ This conclusion is consistent with the observation that Ni-Mo alloys become "activated" even further during the first few hours of operation, concomitant with removal of some of the Mo component. ${ }^{121,133}$

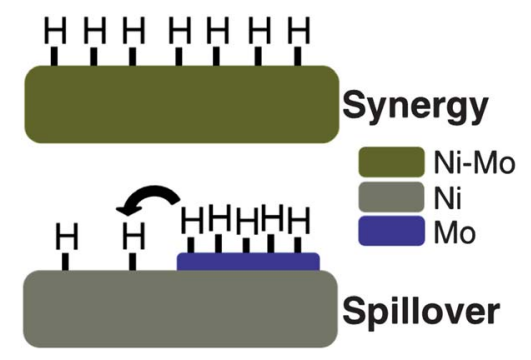

Fig. 7 Schematic depiction of the two proposed mechanisms by which $\mathrm{Ni}-\mathrm{Mo}$ exhibits enhanced activity compared with pure $\mathrm{Ni}$.
Other researchers have claimed that there is an increase in inherent (i.e., per-active site) catalytic activities for Ni-Mo compared to pure Ni, with two possible modes of enhancement (Fig. 7). The first involves electronic synergy, in which bonding in a Ni-Mo alloy or intermetallic phase on the catalyst surface results in a more favorable energy landscape for hydrogen evolution catalysis as a result of mixing elements on either side of the volcano plot for the HER. ${ }^{\mathbf{1 1 9 , 1 3 4 - 1 3 6}}$ Put more simply, Ni-Mo composites are more "platinum-like" than pure Ni or Mo due to an averaging effect between the hydrogen adsorption energies of the respective metals.

The second proposed mechanism for Ni-Mo activity enhancement involves hydrogen spillover. ${ }^{137}$ In this mechanism, the surface of the Ni-Mo composite contains distinct but closely spaced nickel and molybdenum components. Enhanced hydrogen evolution proceeds because one of the components facilitates the first primary step and then transfers the bound hydrogen intermediate to the other component through hydrogen spillover. The second component then completes the reaction. In this case, two distinct species, each with relatively low hydrogen evolution activity, interact cooperatively to facilitate catalysis.

Kinetics analyses of highly active Ni-Mo alloys have yielded Tafel slopes as low as $\sim 30 \mathrm{mV}$ per decade at low overpotentials, as well as very high exchange current densities. ${ }^{120,124}$ Both of these factors play a role in the observed catalytic activities of the composites. High exchange current densities are indicative of very high surface areas for synthesized catalysts, and low Tafel slopes imply that the discharge step, which is likely the slow step in Ni electrocatalysis, is fast on Ni-Mo surfaces. Analysis of a Tafel slope, however, cannot differentiate between electronic synergy versus spillover as the operative mechanism for hydrogen evolution.

\section{Recent work on Ni-Mo}

We have studied Ni-Mo alloys for use in Si-based hydrogen evolving photocathodes. We developed methods by which Ni-Mo alloys can be electrodeposited onto Si substrates and evaluated the resulting composite photocathodes on the basis of thermodynamically based energy conversion efficiency, which is analogous to photovoltaic device efficiency. ${ }^{\mathbf{1 3 8 , 1 3 9}}$ More recently, we developed a method by which Ni-Mo nanopowders can be synthesized independently from a substrate. ${ }^{140}$ These powders were characterized with respect to their composition, morphology, activity, and stability under hydrogen evolution conditions.

Electrodeposited Ni-Mo on Si. Previous methods for electrodepositing highly active Ni-Mo were based on mildly or moderately alkaline deposition solutions, ${ }^{\mathbf{1 1 8 , 1 2 1 , 1 4 1 , 1 4 2}}$ where the molybdate anion is soluble and nickel(II) can be stabilized by a coordinating ligand such as ammonia or pyrophosphate. We found these deposition solutions to be incompatible with $\mathrm{Si}$ photoelectrodes. Instead, we developed a mildly acidic Ni-Mo deposition solution based on nickel sulfamate ${ }^{\mathbf{1 4 3}}$ that allowed for Ni-Mo deposition on $\mathrm{Si}$ surfaces. ${ }^{\mathbf{1 3 8}}$ Catalytically active Ni-Mo can be coated onto Si substrates (Fig. 8) by either potentiostatic or galvanostatic deposition. 

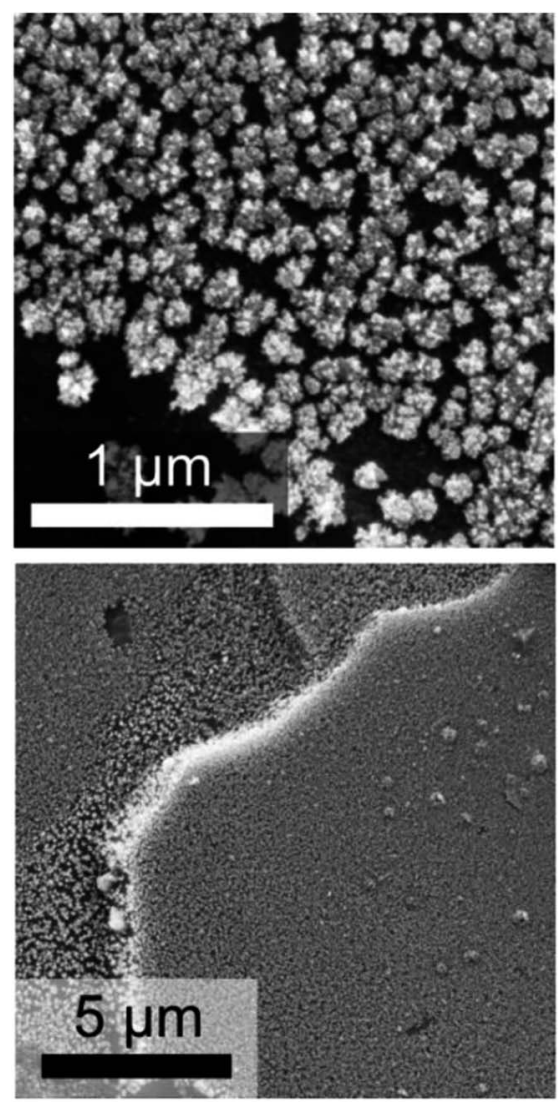

Fig. 8 Scanning electron micrographs of $\mathrm{Ni}-\mathrm{Mo}$ electrocatalyst deposited galvanostatically from sulfamate solution onto a heavily doped, roughened Si substrate.

We employed Ni-Mo, deposited from sulfamate solution, in testing the activity and stability of catalyst films on Si electrodes of various types. ${ }^{\mathbf{1 3 8}}$ First, we evaluated the pure catalytic activity of Ni-Mo deposited onto planar and high-aspect ratio $\mathrm{Si}$ microwire structures. Silicon is a convenient substrate for testing the activities of catalyst coatings, because $\mathrm{Si}$ itself exhibits very low HER activity and it can heavily doped either $\mathrm{p}$ or n-type so as to make it a metallic conductor.

$\mathrm{Ni}$-Mo films on degenerately doped, planar $\mathrm{p}^{+}$-Si electrodes exhibited highly porous morphologies and significantly higher activity toward the HER than electrodeposited Ni metal coatings. Both $\mathrm{Ni}$ and $\mathrm{Ni}-\mathrm{Mo}$, however, exhibited poor stability under strongly acidic conditions, as expected for non-noble transition metal catalysts. Si, on the other hand, exhibited low stability under alkaline conditions. Therefore we performed experiments under mildly acidic conditions, which represented the best compromise between activity and stability for the catalyst and semiconductor components. The high aspect ratio of microwire arrays increases the available surface area over which catalyst may be deposited. As a result, when Ni-Mo was deposited onto $\mathrm{p}^{+}$-Si microwire substrates, the coatings exhibited comparable catalytic activity to Pt deposited onto the same substrates (Fig. 9). We concluded that electrodeposited Ni-Mo alloy is a promising non-noble catalyst for hydrogen evolution on structured Si photoelectrodes.

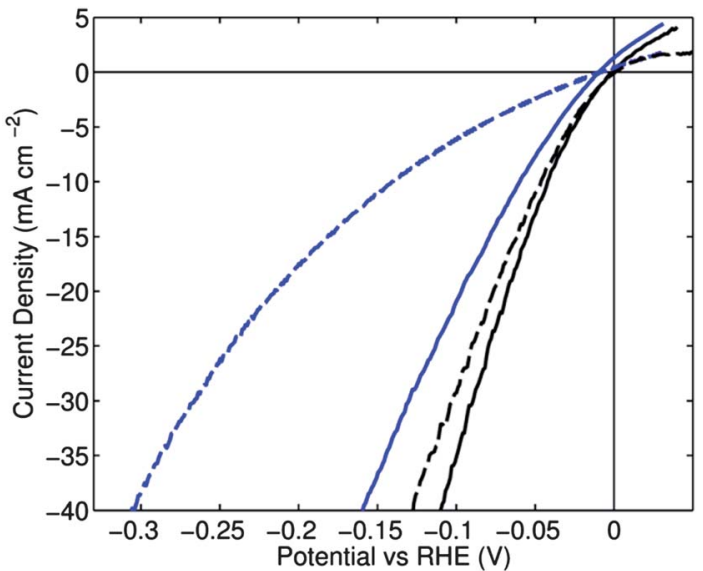

Fig. 9 Polarization curves at $\mathrm{pH} 4.5$ for hydrogen evolution by electrodeposited Ni-Mo (blue) and Pt (black, deposited via electron-beam evaporation) on heavily doped planar (dashed lines) and microwire (solid lines) Si substrates.

Pt can be coupled with Si light absorbers to carry out photoelectrochemical hydrogen evolution with rather high efficiency. ${ }^{\mathbf{1 3 8}}$ We characterized the activities of electrodeposited $\mathrm{Ni}-\mathrm{Mo} / \mathrm{p}-\mathrm{Si}$ photoelectrodes and compared them with photoelectrodes deposited with $\mathrm{Ni}$ and Pt. ${ }^{\mathbf{1 3 8}}$ When coupled directly to p-type Si in planar and microwire geometries, electrodeposited Ni-Mo alloy exhibited higher apparent catalytic activity than pure Ni deposited under the same conditions, and comparable activity to Pt. However, p-Si/Ni-Mo composite electrodes exhibited low photovoltages compared to $\mathrm{p}-\mathrm{Si} / \mathrm{Pt}$ electrodes (Fig. 10). Subsequent efforts in coupling electrodeposited NiMo to $\mathrm{n}^{+} \mathrm{p}$-Si microwire homojunctions yielded photoelectrodes with comparable photovoltages to those using Pt as the HER catalyst. ${ }^{139}$ However, photocurrents for the $\mathrm{n}^{+} \mathrm{p}-\mathrm{Si} / \mathrm{Ni}-\mathrm{Mo}$ composite photoelectrodes were generally lower than those incorporating Pt.

Synthesis and characterization of Ni-Mo nanopowder. Electrodeposition is perhaps not the best method of attaching

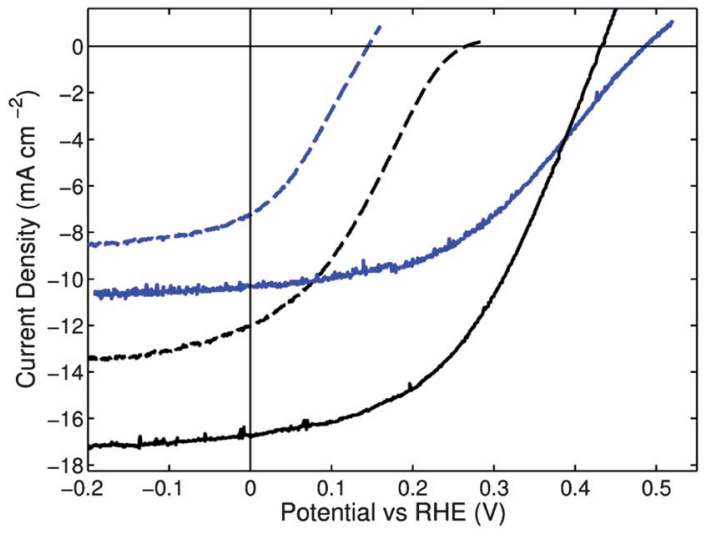

Fig. 10 Polarization curves at $\mathrm{pH} 4.5$ for hydrogen evolution by electrodeposited $\mathrm{Ni}-\mathrm{Mo}$ (blue) and Pt (black) onto p-Si (dashed lines) and $\mathrm{n}^{+} \mathrm{p}-\mathrm{Si}$ (solid lines) microwire substrates under $100 \mathrm{~mW} \mathrm{~cm}$ white light illumination from a tungsten-halogen light source. 
catalysts to semiconductor substrates. The dynamics of electrodeposition of many materials depend critically on the specific surface chemistry of the substrate; in particular, many semiconductor candidates for water splitting photocathodes ( $\mathrm{Si}, \mathrm{GaAs}, \mathrm{InP}$ ) exhibit very sensitive surface chemistry, especially under aqueous conditions. Additionally, in the absence of complex templating approaches, electrodeposition results in conformal coverage of a substrate with a catalyst layer. Such coverage is desirable for "dark" electrocatalysis, where usually the substrate is inactive compared to the catalyst coating, and so maximal coverage by the catalyst layer is important. However, for semiconductor photocatalysis, conformal coverage of catalyst will attenuate light absorption. Heller did not observe significant absorption losses on $\mathrm{p}$-InP coated with thin layers of Pt-group metals, ${ }^{144-147}$ but a much larger mass of non-noble (e.g., $\mathrm{Ni}-\mathrm{Mo})$ material is required to attain comparable catalytic activity, resulting in high optical opacity for the catalyst layer (Fig. 11).

Owing to challenges posed by sensitive surface chemistry and parasitic light absorption, as well as the difficulty of fully characterizing the composition and properties of electrodeposited materials, we developed a chemical method for synthesizing highly active Ni-Mo "nanopowder" in large quantities. ${ }^{140}$ First, a mixed Ni-Mo oxide was precipitated by heating an ammonia solution of nickel(II) and ammonium molybdate in diethylene glycol. The intermediate oxide powder was reduced under a hydrogen-containing atmosphere at elevated temperature. The result was a nanoparticulate powder of Ni-Mo alloy that could be made with a variety of compositions and processed into films on substrates. Ni-Mo nanopowder films exhibited high catalytic activity for hydrogen evolution in compositions ranging from $10-40 \%$ Mo by mole.

Our Ni-Mo nanopowder synthesis was modeled after previous work in synthesizing highly HER-active Ni-Mo coatings ${ }^{120}$ and Ni-Mo mixed oxides. ${ }^{148,149}$ Unlike previous methods, however, our synthesis did not require deposition of Ni-Mo precursors directly onto a substrate. As a result, it is easy to scale to large quantities and to characterize the physical properties of the catalyst without the convoluting effects of a substrate. The

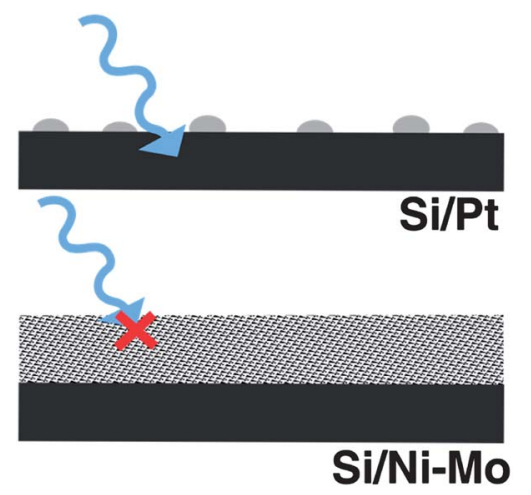

Fig. 11 Schematic of photoelectrodes coated with a thin layer of noble metal catalyst (top), allowing most solar photons to transmit. Conversely, a thick layer of non-noble metal catalyst (bottom) attenuates light absorption by the underlying substrate.

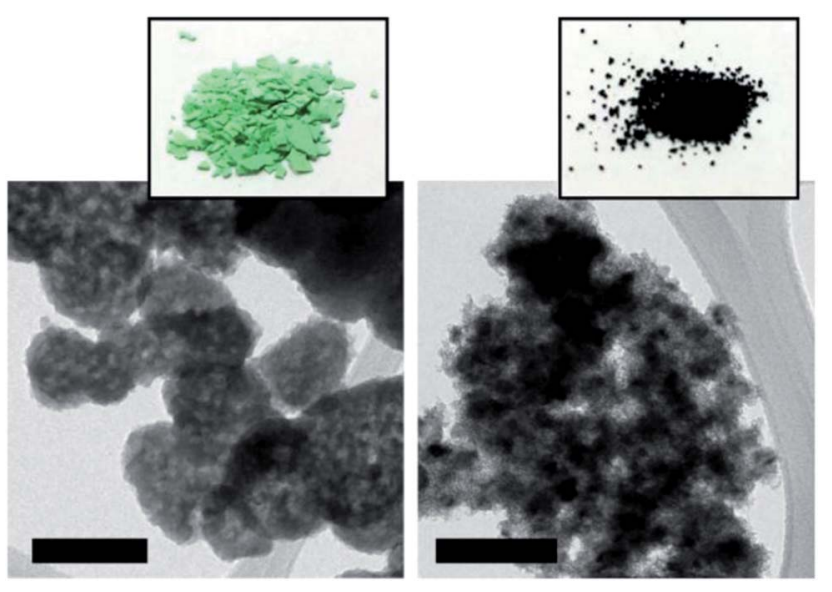

Fig. 12 Transmission electron micrographs (TEM) and optical images (insets) of the intermediate $\mathrm{Ni}-\mathrm{Mo}$ oxide (left) and $\mathrm{Ni}-\mathrm{Mo}$ nanopowder (right). Scale bars in the TEM images are $100 \mathrm{~nm}$.

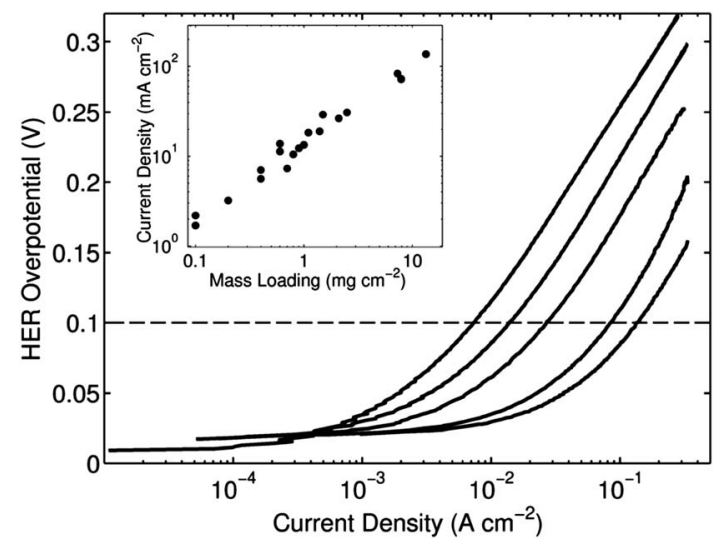

Fig. 13 Tafel plot showing catalytic HER behaviors of selected Ni-Mo nanopowder samples with various mass loadings on Ti-foil substrates in $1 \mathrm{M} \mathrm{NaOH}$ at room temperature. Higher activities correspond to electrodes with higher mass loadings. The inset shows current densities at $\eta=100 \mathrm{mV}$ for the HER over two orders of magnitude in catalyst mass loading.

pale green oxide was amorphous and nanoparticulate (Fig. 12). The product Ni-Mo nanopowder was black, crystalline, and highly porous. Films could be loaded onto inert electrode substrates with varying mass loading to determine the massspecific catalytic activity. We observed a power law relationship between mass loading and current density at a given overpotential under alkaline conditions (Fig. 13), consistent with "diminishing returns" in activity with increased catalyst loading, as thicker Ni-Mo coatings obscured underlayers from access to reactant.

We also found that Tafel responses for Ni-Mo nanopowders were nonlinear at low overpotentials, especially at high mass loadings. This nonlinear behavior might imply a complex mechanism under operating conditions at low overpotentials. The Tafel expression assumes the rate of the forward reaction far exceeds that of the back reaction. ${ }^{113}$ For most electrochemical processes at overpotentials of $<120 \mathrm{mV}$, such an 
assumption does not hold. In this potential range, a ButlerVolmer rate law, which accounts for the back reaction rate and does not exhibit a linear relationship between $\eta$ and $\log (i)$, must be employed. Further analysis, especially employing in-operando spectroscopic techniques, should be helpful in probing kinetics and intermediates of hydrogen evolution on Ni-Mo composites.

Stability and applications of $\mathrm{Ni}-\mathrm{Mo}$ nanopowder. $\mathrm{Ni}-\mathrm{Mo}$ nanopowders exhibited very high stability under hydrogen evolution conditions in alkaline solution. In fact, we observed a slight enhancement in activity over 100 hours of continuous operation at room temperature, consistent with previous observations of very high activity and stability in concentrated alkaline solution for thousands of hours at elevated temperature. ${ }^{\mathbf{1 1 9}}$

Under strongly acidic conditions, Ni-Mo nanopowders exhibited low stability. Although the initial activity was high even in $0.5 \mathrm{M} \mathrm{H}_{2} \mathrm{SO}_{4}$, Ni-Mo catalyst coatings with mass loadings of several $\mathrm{mg} \mathrm{cm} \mathrm{cm}^{-2}$ rapidly degraded after several hours. We concluded that such coatings are stable enough under acidic conditions for laboratory testing but are not commercially viable in proton exchange membrane electrolysis systems. A key ongoing challenge is increasing the stability of Ni-Mo materials under acidic conditions, or stabilization of photocathode absorbers, such as $\mathrm{Si}$, under alkaline conditions.

Recent efforts have shown that Mo-containing catalysts can be stabilized under acidic conditions with the addition of nitrogen and carbon. ${ }^{\mathbf{1 5 0 , 1 5 1}}$ Chen and coworkers also showed that a Mo-rich Ni-Mo nitride, supported on carbon black, exhibited good activity that was largely retained even after cycling continuously to very positive electrochemical potentials in $0.1 \mathrm{M} \mathrm{HClO}_{4} \cdot{ }^{152}$ Pure carbon-supported Ni-Mo controls tested under the same conditions by these researchers also exhibited fairly high stability, but very low catalytic activity. Incorporation of carbon, nitrogen, and sulfur additives has been shown to enhance the activity and stability of Co and Fe-based catalysts toward oxygen reduction under acidic conditions. ${ }^{153}$ It is possible that the mode of stability enhancement in both cases is similar.

Additional work on Ni-Mo composites has demonstrated potentially viable operation in a full solar water splitting system. Nocera and coworkers reported the use of a ternary Ni-Mo-Zn electrocatalyst electrodeposited onto the cathode terminal of an amorphous Si triple-junction solar cell. ${ }^{\mathbf{1 5 4 , 1 5 5}}$ When paired with a suitable water oxidation catalyst, a full "artificial leaf" was fabricated that was capable of carrying out water splitting at neutral $\mathrm{pH}$ without the need for an applied bias. A similar amorphous-silicon based water splitting system, reported by Rocheleau, operated under alkaline conditions with a related Co-Mo HER catalyst. ${ }^{156}$ These demonstration water splitting systems are encouraging indications of the plausibility of solar fuels generation using earth-abundant elements.

\section{Concluding remarks}

Great progress has been made in the last several decades on catalysis of the HER by molecular and solid-state compounds containing earth-abundant metals. For cobalt-catalyzed hydrogen evolution, we have shown that the predominant pathway involves a highly reactive $\mathrm{Co}^{\mathrm{II}}-\mathrm{H}$ intermediate, generated by reduction of $\mathrm{Co}^{\mathrm{III}}-\mathrm{H}$; and our work with $\mathrm{Ni}-\mathrm{Mo}$ has demonstrated that non-noble solid HER catalysts are active enough to be useful for efficient solar hydrogen generation.

Challenges remain in the development of molecular and solid materials for solar-driven hydrogen evolution. Molecular systems, in spite of their thorough characterization, do not exhibit sufficiently low overpotentials or aqueous stability to be used in demonstration devices. Earth-abundant solid catalysts such as Ni-Mo suffer from high mass-loading requirements resulting in unwanted light absorption by the catalyst layer. Additionally, many earth-abundant solid catalysts, including $\mathrm{Ni}-\mathrm{Mo}$, are not stable under acidic conditions. Incorporation of carbon, nitrogen, and sulfur, however, appears to be a promising strategy to increase their stability.

As the high HER activity of Ni-Mo is not yet understood, there is a clear need to design experiments to differentiate between electronic versus spillover processes. For molecular Co complexes, the key challenge is developing ligand frameworks that tune the $\mathrm{Co}^{\mathrm{I} / 0}$ reduction potential sufficiently positive to give low overpotential operation while retaining catalytic activity. Similar arguments can be made for tuning the reduction potentials of molecular catalysts incorporating Fe, Mo, and $\mathrm{Ni}$. In all cases, understanding the predominant pathways for molecular and solid-state hydrogen evolution will continue to aid the design of more efficient catalysts.

\section{Acknowledgements}

This work was supported by the National Science Foundation "Powering the Planet" Center for Chemical Innovation (CHE-1305124). S.C.M. acknowledges the National Science Foundation for a CCI postdoctoral fellowship. J.R.M. additionally acknowledges the U.S. Department of Energy, Office of Science, for a graduate research fellowship.

\section{References}

1 N. S. Lewis and D. G. Nocera, Proc. Natl. Acad. Sci. U. S. A., 2006, 103, 15729-15735.

2 S. Reichelstein and M. Yorston, Energy Policy, 2013, 55, 117127.

3 N. S. Lewis, Science, 2007, 315, 798-801.

4 J. Rugolo and M. J. Aziz, Energy Environ. Sci., 2012, 5, 7151.

5 Annual Energy Review 2011 0610030116, U.S. Energy Information Administration, 2011.

6 J. P. Deane, B. P. Ó Gallachóir and E. J. McKeogh, Renewable Sustainable Energy Rev., 2010, 14, 1293-1302.

7 C.-J. Yang and R. B. Jackson, Renewable Sustainable Energy Rev., 2011, 15, 839-844.

8 V. Srinivasan, D. Hafemeister, B. Levi, M. Levine and P. Schwartz, AIP Conf. Proc., 2008, 1044, 283-296.

9 J. Ivy, Summary of Electrolytic Hydrogen Production Milestone Completion Report, U.S. Department of Energy, 2004. 
10 S. Satyapal, J. Petrovic, C. Read, G. Thomas and G. Ordaz, Catal. Today, 2007, 120, 246-256.

11 M. Walter, E. Warren, J. McKone, S. Boettcher, M. Qixi, L. Santori and N. Lewis, Chem. Rev., 2010, 110, 6446-6473.

12 K. J. Young, L. a. Martini, R. L. Milot, R. C. Snoeberger, V. S. Batista, C. a. Schmuttenmaer, R. H. Crabtree and G. W. Brudvig, Coord. Chem. Rev., 2012, 256, 2503-2520.

13 Y. Tachibana, L. Vayssieres and J. R. Durrant, Nat. Photonics, 2012, 6, 511-518.

14 J. Newman, P. G. Hoertz, C. A. Bonino and J. A. Trainham, J. Electrochem. Soc., 2012, 159, A1722-A1729.

15 Y. Lin, G. Yuan, R. Liu, S. Zhou, S. W. Sheehan and D. Wang, Chem. Phys. Lett., 2011, 507, 209-215.

16 B. a. Pinaud, J. D. Benck, L. C. Seitz, A. J. Forman, Z. Chen, T. G. Deutsch, B. D. James, K. N. Baum, G. N. Baum, S. Ardo, H. Wang, E. Miller and T. F. Jaramillo, Energy Environ. Sci., 2013, 6, 1983-2002.

17 B. D. James, G. N. Baum, J. Perez and K. N. Baum, DOE Report, 2009, GS-10F-009.

18 P. C. K. Vesborg and T. F. Jaramillo, RSC Adv., 2012, 2, 7933.

19 J. L. Dempsey, B. S. Brunschwig, J. R. Winkler and H. B. Gray, Acc. Chem. Res., 2009, 42, 1995-2004.

20 P. Du and R. Eisenberg, Energy Environ. Sci., 2012, 5, 60126021.

21 V. Artero and M. Fontecave, Coord. Chem. Rev., 2005, 249, 1518-1535.

22 V. Artero, M. Chavarot-Kerlidou and M. Fontecave, Angew. Chem., Int. Ed., 2011, 50, 7238-7266.

23 M. Y. Darensbourg, E. J. Lyon and J. J. Smee, Coord. Chem. Rev., 2000, 206, 533-561.

24 I. P. Georgakaki, L. M. Thomson, E. J. Lyon, M. B. Hall and M. Y. Darensbourg, Coord. Chem. Rev., 2003, 238-239, 255266.

25 M. R. DuBois and D. L. DuBois, Chem. Soc. Rev., 2009, 38, 62-72.

26 M. R. Dubois and D. L. Dubois, Acc. Chem. Res., 2009, 42, 1974-1982.

27 V. S. Thoi, Y. Sun, J. R. Long and C. J. Chang, Chem. Soc. Rev., 2013, 42, 2388-2400.

28 W. T. Eckenhoff, W. R. McNamara, P. Du and R. Eisenberg, Biochim. Biophys. Acta, 2013, 1827, 958-973.

29 S. Losse, J. G. Vos and S. Rau, Coord. Chem. Rev., 2010, 254, 2492-2504.

30 V. Artero and M. Fontecave, Chem. Sci., 2013, 42, 2338.

31 W. T. Eckenhoff and R. Eisenberg, Dalton Trans., 2012, 41, 13004.

32 M. Frey, ChemBioChem, 2002, 3, 153-160.

33 J. C. Fontecilla-Camps, A. Volbeda, C. Cavazza and Y. Nicolet, Chem. Rev., 2007, 107, 4273-4303.

34 A. C. Marr, D. J. E. Spencer and M. Schroder, Coord. Chem. Rev., 2001, 219, 1055-1074.

35 M. Y. Darensbourg, E. J. Lyon, X. Zhao and I. P. Georgakaki, Proc. Natl. Acad. Sci. U. S. A., 2003, 100, 3683-3688.

36 D. J. Evans and C. J. Pickett, Chem. Soc. Rev., 2003, 32, 268275.

37 M. L. Helm, M. P. Stewart, R. M. Bullock, M. R. DuBois and D. L. DuBois, Science, 2011, 333, 863-866.
38 A. D. Wilson, R. K. Shoemaker, A. Miedaner, J. T. Muckerman, D. L. DuBois and M. R. DuBois, Proc. Natl. Acad. Sci. U. S. A., 2007, 104, 6951-6956.

39 H. I. Karunadasa, C. J. Chang and J. R. Long, Nature, 2010, 464, 1329-1333.

40 H. I. Karunadasa, E. Montalvo, Y. Sun, M. Majda, J. R. Long and C. J. Chang, Science, 2012, 335, 698-702.

41 Y. Sun, J. P. Bigi, N. A. Piro, M. L. Tang, J. R. Long and C. J. Chang, J. Am. Chem. Soc., 2011, 133, 9212-9215.

42 A. E. King, Y. Surendranath, N. A. Piro, J. P. Bigi, J. R. Long and C. J. Chang, Chem. Sci., 2013, 4, 1578.

43 M. Nippe, R. S. Khnayzer, J. A. Panetier, D. Z. Zee, B. S. Olaiya, M. Head-Gordon, C. J. Chang, F. N. Castellano and J. R. Long, Chem. Sci., 2013, 4, 3934.

44 Y. Sun, J. Sun, J. R. Long, P. Yang and C. J. Chang, Chem. Sci., 2013, 4, 118.

45 P. Connolly and J. H. Espenson, Inorg. Chem., 1986, 25, 2684-2688.

46 X. L. Hu, B. M. Cossairt, B. S. Brunschwig, N. S. Lewis and J. C. Peters, Chem. Commun., 2005, 4723-4725.

47 X. Hu, B. S. Brunschwig and J. C. Peters, J. Am. Chem. Soc., 2007, 129, 8988-8998.

48 M. Wang, L. Chen and L. Sun, Energy Environ. Sci., 2012, 5, 6763-6778.

49 P.-A. Jacques, V. Artero, J. Pecaut and M. Fontecave, Proc. Natl. Acad. Sci. U. S. A., 2009, 106, 20627-20632.

50 W. R. McNamara, Z. Han, P. J. Alperin, W. W. Brennessel, P. L. Holland and R. Eisenberg, J. Am. Chem. Soc., 2011, 133, 15368-15371.

51 W. R. McNamara, Z. Han, C.-J. Yin, W. W. Brennessel, P. L. Holland and R. Eisenberg, Proc. Natl. Acad. Sci. U. S. A., 2012, 109, 15594-15599.

52 B. D. Stubbert, J. C. Peters and H. B. Gray, J. Am. Chem. Soc., 2011, 133, 18070-18073.

53 I. Bhugun, D. Lexa and J.-M. Savéant, J. Am. Chem. Soc., 1996, 118, 3982-3983.

54 J.-M. Savéant, Chem. Rev., 2008, 108, 2348-2378.

55 C. Costentin, M. Robert and J.-M. Savéant, Acc. Chem. Res., 2010, 43, 1019-1029.

56 C. P. Andrieux, C. Blocman, J. M. Dumas-Bouchiat, F. M'Halla and J. M. Savéant, J. Electroanal. Chem., 1980, 113, 19-40.

57 S. Kaur-Ghumaan, L. Schwartz, R. Lomoth, M. Stein and S. Ott, Angew. Chem., Int. Ed., 2010, 49, 8033-8036.

58 L. Schwartza, P. S. Singha, L. Erikssonb, R. Lomotha and S. Otta, C. R. Chim., 2008, 11, 875-889.

59 C. Tard and C. J. Pickett, Chem. Rev., 2009, 109, 2245-2274.

60 J. C. Fontecilla and S. W. Ragsdale, Adv. Inorg. Chem., 1999, 47, 283-333.

61 S. Ezzaher, P.-Y. Orain, J.-F. Capon, F. Gloaguen, F. Y. Pétillon, T. Roisnel, P. Schollhammer and J. Talarmin, Chem. Commun., 2008, 2547-2549.

62 G. A. N. Felton, C. A. Mebi, B. J. Petro, A. K. Vannucci, D. H. Evans, R. S. Glass and D. L. Lichtenberger, J. Organomet. Chem., 2009, 17, 2681-2699.

63 Z. Wang, W. Jiang, J. Liu, W. Jiang, Y. Wang, B. Åkerman and L. Sun, J. Organomet. Chem., 2008, 693, 2828-2834. 
64 F. Huo, J. Hou, G. Chen, D. Guo and X. Peng, Eur. J. Inorg. Chem., 2010, 3942-3951.

65 J. W. Tye, J. Lee, H.-W. Wang, R. Mejia-Rodriguez, J. H. Reibenspies, M. B. Hall and M. Y. Darensbourg, Inorg. Chem., 2005, 44, 5550-5552.

66 M. Y. Darensbourg, E. J. Lyon and J. J. Smee, Coord. Chem. Rev., 2000, 206-207, 533-561.

67 M. T. Olsen, A. K. Justice, F. Gloaguen, T. B. Rauchfuss and S. R. Wilson, Inorg. Chem., 2008, 47, 11816-11824.

68 A. M. Royer, M. Stagni-Salomone, T. B. Rauchfuss and W. Meyer-Klaucke, J. Am. Chem. Soc., 2010, 132, 1699717003.

69 T. Liu and M. Y. Darensbourg, J. Am. Chem. Soc., 2007, 129, 7008-7009.

70 M. J. Rose, H. B. Gray and J. R. Winkler, J. Am. Chem. Soc., 2012, 134, 8310-8313.

71 T. H. Chao and J. H. Espenson, J. Am. Chem. Soc., 1978, 100, 129-133.

72 C. Baffert, V. Artero and M. Fontecave, Inorg. Chem., 2007, 46, 1817-1824.

73 J. L. Dempsey, J. R. Winkler and H. B. Gray, J. Am. Chem. Soc., 2010, 132, 1060-1065.

74 J. L. Dempsey, J. R. Winkler and H. B. Gray, J. Am. Chem. Soc., 2010, 132, 16774-16776.

75 T. Lazarides, T. McCormick, P. Du, G. Luo, B. Lindley and R. Eisenberg, J. Am. Chem. Soc., 2009, 131, 9192-9194.

76 E. Szajna-Fuller and A. Bakac, Eur. J. Inorg. Chem., 2010, 2488-2494.

77 A. Bhattacharjee, M. Chavarot-Kerlidou, E. S. Andreiadis, M. Fontecave, M. J. Field and V. Artero, Inorg. Chem., 2012, 51, 7087-7093.

78 G. N. Schrauzer and R. J. Holland, J. Am. Chem. Soc., 1971, 93, 1505-1506.

79 B. H. Solis and S. Hammes-Schiffer, J. Am. Chem. Soc., 2011, 133, 19036-19039.

80 B. H. Solis and S. Hammes-Schiffer, Inorg. Chem., 2011, 50, 11252-11262.

81 J. T. Muckerman and E. Fujita, Chem. Commun., 2011, 47, 12456-12458.

82 B. H. Solis, Y. Yu and S. Hammes-Schiffer, Inorg. Chem., 2013, 52, 6994.

83 S. C. Marinescu, J. R. Winkler and H. B. Gray, Proc. Natl. Acad. Sci. U. S. A., 2012, 109, 15127-15131.

84 C. A. Ghilardi, S. Midollini and L. Sacconi, Inorg. Chem., 1975, 14, 1790-1795.

85 C. Bianchini, C. Mealli, A. Meli, M. Peruzzini and F. Zanobini, J. Am. Chem. Soc., 1988, 110, 8725-8726.

86 D. M. Heinekey, A. Liegeois and M. Vanroon, J. Am. Chem. Soc., 1994, 116, 8388-8389.

87 D. M. Heinekey and M. van Roon, J. Am. Chem. Soc., 1996, 118, 12134-12140.

88 J. Mautz, K. Heinze, H. Wadepohl and G. Huttner, Eur. J. Inorg. Chem., 2008, 1413-1422.

89 U. Winterhalter, L. Zsolnai, P. Kircher, K. Heinze and G. Huttner, Eur. J. Inorg. Chem., 2001, 89-103.

90 A. Rahman, W. G. Jackson, A. C. Willis and A. D. Rae, Chem. Commun., 2003, 2748-2749.
91 U. Koelle and S. Ohst, Inorg. Chem., 1986, 25, 2689-2694.

92 R. Ciancanelli, B. C. Noll, D. L. DuBois and M. R. DuBois, J. Am. Chem. Soc., 2002, 124, 2984-2992.

93 C. Bianchini, D. Masi, C. Mealli, A. Meli and M. Sabat, Gazz. Chim. Ital., 1986, 116, 201.

94 C. H. Lee, D. K. Dogutan and D. G. Nocera, J. Am. Chem. Soc., 2011, 133, 8775-8777.

95 M. M. Roubelakis, D. K. Bediako, D. K. Dogutan and D. G. Nocera, Energy Environ. Sci., 2012, 5, 7737-7740.

96 C. N. Valdez, J. L. Dempsey, B. S. Brunschwig, J. R. Winkler and H. B. Gray, Proc. Natl. Acad. Sci. U. S. A., 2012, 109, 15589-15593.

97 L. A. Berben and J. C. Peters, Chem. Commun., 2010, 46, 398-400.

98 A. Le Goff, V. Artero, B. Jousselme, P. D. Tran, N. Guillet, R. Métayé, A. Fihri, S. Palacin and M. Fontecave, Science, 2009, 326, 1384-1387.

99 E. S. Andreiadis, P.-A. Jacques, P. D. Tran, A. Leyris, M. Chavarot-Kerlidou, B. Jousselme, M. Matheron, J. Pécaut, S. Palacin, M. Fontecave and V. Artero, Nat. Chem., 2013, 5, 48-53.

100 G. F. Moore and I. D. Sharp, J. Phys. Chem. Lett., 2013, 4, 568-572.

101 A. Krawicz, J. Yang, E. Anzenberg, J. Yano, I. D. Sharp and G. F. Moore, J. Am. Chem. Soc., 2013, 135, 11861-11868.

102 J. Tafel, Z. Phys. Chem-Stoch. Ve., 1905, 50, 641-712.

103 J. Tafel and K. Naumann, Z. Phys. Chem-Stoch. Ve., 1905, 50, 713-752.

104 S. Trasatti, in Advances in Electrochemical Science and Engineering, ed. H. Gerischer and C. W. Tobias, VCH, Weinheim, Germany, 1992, vol. 2, pp. 1-85.

105 H. Gerischer, Bull. Soc. Chim. Belg., 1958, 67, 506-527.

106 R. Parsons, Trans. Faraday Soc., 1958, 54, 1053-1063.

107 M. Miles, J. Electroanal. Chem., 1975, 60, 89-96.

108 S. Trasatti, J. Electroanal. Chem., 1972, 39, 163-184.

109 J. Greeley, T. F. Jaramillo, J. Bonde, I. Chorkendorff and J. K. Norskov, Nat. Mater., 2006, 5, 909-913.

110 J. Greeley, J. Norskov, L. Kibler, A. El-Aziz and D. Kolb, ChemPhysChem, 2006, 7, 1032-1035.

111 J. K. Norskov, T. Bligaard, A. Logadottir, J. R. Kitchin, J. G. Chen, S. Pandelov and U. Stimming, J. Electrochem. Soc., 2005, 152, J23-J26.

112 A. Laursen and A. Varela, J. Chem. Educ., 2012, 89, 15951599.

113 A. J. Bard and L. R. Faulkner, Electrochemical Methods: Fundamentals and Applications, Wiley, 2 edn, 2000.

114 B. Conway, Electrochim. Acta, 1964, 9, 1599-1615.

115 A. B. Laursen, S. Kegnæs, S. Dahl and I. Chorkendorff, Energy Environ. Sci., 2012, 5, 5577.

116 D. Merki and X. Hu, Energy Environ. Sci., 2011, 4, 3878.

117 D. W. Ernst and M. L. Holt, J. Electrochem. Soc., 1958, 105, 686-692.

118 N. W. Hovey, A. Krohn and J. Hanneken, J. Electrochem. Soc., 1963, 110, 362-366.

119 D. Brown, M. Mahmood, M. Man and A. Turner, Electrochim. Acta, 1984, 29, 1551-1556. 
120 D. Brown, M. Mahmood, A. Turner, S. Hall and P. Fogarty, Int. J. Hydrogen Energy, 1982, 7, 405-410.

121 J. Z. O. Stachurski, D. Pouli, J. A. Ripa and G. F. Pokrzyk, US Pat., 4,354,915, 1982.

122 B. Conway, H. Angersteinkozlowska, M. Sattar and B. Tilak, J. Electrochem. Soc., 1983, 130, 1825-1836.

123 B. Conway and L. Bai, J. Chem. Soc., Faraday Trans. 1, 1985, 81, 1841-1862.

124 B. Conway and L. Bai, Int. J. Hydrogen Energy, 1986, 11, 533540.

125 B. Conway and B. Tilak, Electrochim. Acta, 2002, 47, 35713594.

126 I. Raj, Int. J. Hydrogen Energy, 1992, 17, 413-421.

127 I. Raj, J. Mater. Sci., 1993, 28, 4375-4382.

128 I. Raj, Bull. Electrochem., 1999, 15, 519-523.

129 I. Raj and K. Vasu, J. Appl. Electrochem., 1990, 20, 32-38.

130 I. Raj and K. Vasu, J. Appl. Electrochem., 1992, 22, 471-477.

131 I. Raj and V. Venkatesan, Int. J. Hydrogen Energy, 1988, 13, 215-223.

132 J. Jaksic, M. Vojnovic and N. Krstajic, Electrochim. Acta, 2000, 45, 4151-4158.

133 A. Kawashima, E. Akiyama, H. Habazaki and K. Hashimoto, Mater. Sci. Eng., A, 1997, 226, 905-909.

134 C. Fan, D. Piron, A. Sleb and P. Paradis, J. Electrochem. Soc., 1994, 141, 382-387.

135 Q. Han, S. Cui, N. Pu, J. Chen, K. Liu and X. Wei, Int. J. Hydrogen Energy, 2010, 35, 5194-5201.

136 E. Navarro-Flores, Z. Chong and S. Omanovic, J. Mol. Catal. A: Chem., 2005, 226, 179-197.

137 J. G. Highfield, E. Claude and K. Oguro, Electrochim. Acta, 1999, 44, 2805-2814.

138 S. W. Boettcher, E. L. Warren, M. C. Putnam, E. L. Santori, D. Turner-Evans, M. D. Kelzenberg, M. G. Walter, J. R. McKone, B. S. Brunschwig, H. A. Atwater and N. S. Lewis, J. Am. Chem. Soc., 2011, 133, 12161219.

139 E. L. Warren, J. R. McKone, H. A. Atwater, H. B. Gray and N. S. Lewis, Energy Environ. Sci., 2012, 5, 9653.
140 J. R. McKone, B. Sadtler, C. A. Werlang, N. S. Lewis and H. B. Gray, ACS Catal., 2013, 3, 166-169.

141 E. Chassaing, K. Quang and R. Wiart, J. Appl. Electrochem., 1989, 19, 839-843.

142 N. Krstajic, V. Jovic, L. Gajic-Krstajic, B. Jovic, A. Antozzi and G. Martelli, Int. J. Hydrogen Energy, 2008, 33, 36763687.

143 Y. Tsuru, M. Nomura and F. R. Foulkes, J. Appl. Electrochem., 2002, 32, 629-634.

144 E. Aharon-Shalom and A. Heller, J. Electrochem. Soc., 1982, 129, 2865.

145 Y. Degani, T. Sheng, A. Heller and D. Aspnes, J. Electroanal. Chem., 1987, 228, 167-178.

146 A. Heller, E. Aharon-Shalom, W. A. Bonner and B. Miller, J. Am. Chem. Soc., 1982, 104, 6942-6948.

147 A. Heller and R. G. Vadimsky, Phys. Rev. Lett., 1981, 46, 1153.

148 D. Levin, S. L. Soled and J. Y. Ying, Inorg. Chem., 1996, 35, 4191-4197.

149 P. Schmitt, N. Brem, S. Schunk and C. Feldmann, Adv. Funct. Mater., 2011, 21, 3037-3046.

150 W.-F. Chen, S. Iyer, S. Iyer, K. Sasaki, C.-H. Wang, Y. Zhu, J. T. Muckerman and E. Fujita, Energy Environ. Sci., 2013, 6, 1818.

151 W.-F. Chen, C.-H. Wang, K. Sasaki, N. Marinkovic, W. Xu, J. T. Muckerman, Y. Zhu and R. R. Adzic, Energy Environ. Sci., 2013, 6, 943.

152 W.-F. Chen, K. Sasaki, C. Ma, A. I. Frenkel, N. Marinkovic, J. T. Muckerman, Y. Zhu and R. R. Adzic, Angew. Chem., Int. Ed., 2012, 51, 6131-6135.

153 Z. Chen, D. Higgins, A. Yu, L. Zhang and J. Zhang, Energy Environ. Sci., 2011, 4, 3167.

154 D. G. Nocera, Acc. Chem. Res., 2012, 45, 767-776.

155 S. Y. Reece, J. a. Hamel, K. Sung, T. D. Jarvi, A. J. Esswein, J. J. H. Pijpers and D. G. Nocera, Science, 2011, 334, 645648.

156 R. E. Rocheleau, E. L. Miller and A. Misra, Energy Fuels, 1998, 12, 3-10. 